\title{
The Political Economy of Unfinished Development Projects: Corruption, Clientelism, or Collective Choice?
}

\author{
Martin J. Williams * \\ Forthcoming: American Political Science Review, November 2017
}

\begin{abstract}
Development projects like schools and latrines are popular with politicians and voters alike, yet many developing countries are littered with half-finished projects that were abandoned mid-construction. Using an original database of over 14,000 small development projects in Ghana, I estimate that one-third of projects that start are never completed, consuming nearly one-fifth of all local government investment. I develop a theory of project non-completion as the outcome of a dynamically inconsistent collective choice process among political actors facing commitment problems in contexts of limited resources. I find evidence consistent with key predictions of this theory, but inconsistent with alternative explanations based on corruption or clientelism. I show that fiscal institutions can increase completion rates by mitigating the operational consequences of these collective choice failures. These findings have theoretical and methodological implications for distributive politics, the design of intergovernmental transfers and aid, and the development of state capacity.
\end{abstract}

*Associate Professor in Public Management, University of Oxford, Blavatnik School of Government, Radcliffe Observatory Quarter, Oxford OX2 6GG, United Kingdom. Email: martin.williams@bsg.ox.ac.uk. This version of the paper is for private research and study only and may not be redistributed. This project has benefited from data and discussions with individuals from numerous institutions in Ghana, including the National Development Planning Commission, Ministry of Local Government and Rural Development, Local Government Service Secretariat, Ministry of Finance, District Assemblies Common Fund Administrator, Ghana Audit Service, World Bank, Ministry of Education, and GETFund Secretariat. However, the findings and opinions herein should not be attributed to any of these institutions. I am grateful for comments from Nana Agyekum-Dwamena, Ben Ansell, Daniel Berger, Catherine Boone, Christian Breunig, Stefano Caria, Ali Cirone, Darin Christensen, Patrick Dunleavy, Douglas Gollin, Nahomi Ichino, Ryan Jablonski, Julien Labonne, Noah Nathan, Pia Raffler, Imran Rasul, Dan Rogger, Anisha Sharma, Joachim Wehner, Erik Wibbels, Stephane Wolton, three anonymous reviewers, and workshop participants at the LSE, Ghana CSTC, ODI, DFID, EPSA, APSA, PacDev, Princeton, Georgetown, IMF, ABCDE, MPSA, WGAPE, and the Ghana Ministry of Finance, and to Nahomi Ichino and Erik Wibbels for sharing data. This research was funded by International Growth Centre grant 1-VRG-VGHA-VXXXX-89105. Allan Kasapa, Joseph Napen, and Abdul-Kadir Mumuni provided excellent research assistance. Any remaining errors are my own. 


\section{Introduction}

The provision of social infrastructure is a crucial function of government in developing countries, where access to basic facilities like schools, clinics, and latrines is often low. These targeted, visible, and popular projects are also exactly the type of public goods that politicians seek to deliver in theories of pork barrel politics, tactical redistribution, and credit claiming. Yet it is anecdotally common for governments in developing countries to start work on such projects but never actually complete them, leaving behind half-finished projects of no value to users and voters. Though widely remarked upon and substantively important, the extent and causes of this phenomenon have received surprisingly little attention. ${ }^{1}$

Unfinished projects also pose a theoretical puzzle: conditional on a government having started a project, why would the same government subsequently not finish the project? ${ }^{2}$ This question is not well explained by existing theories of politically motivated misallocation of public expenditure associated with distributive politics and clientelism, in which inefficiency arises due to the tactical targeting of expenditure (Cox and McCubbins 1986; Dixit and Londregan 1996; Golden and Min 2013) or over- or under-spending on infrastructure relative to private transfers (Keefer 2007; Robinson and Verdier 2013). Similarly, although corruption has been the overwhelming focus of studies of the implementation of public good provision in developing countries (Banerjee, Hanna, and Mullainathan 2013) and the allocation of infrastructure contracts to political supporters has been widely remarked (Samuels 2002), corruption in project delivery need not lead to non-completion of the project. Indeed, when corruption takes

\footnotetext{
${ }^{1}$ For instance, Samuels $(2002,852)$ refers in passing to "the literally thousands of unfinished pork-barrel projects that dot the Brazilian countryside", and there are reportedly 19,000 abandoned government projects in Nigeria (Vanguard 2016). In the only large-sample study of project completion, to my knowledge, Rasul and Rogger (2016) estimate that 25 percent of government projects in Nigeria that start are not completed.

${ }^{2}$ To focus on the core theoretical question, I abstract from considerations of regime change or electoral alternation, the identity or capacity of politicians and bureaucrats, project complexity, and other environmental shocks. These factors are either controlled for in my empirical research design or are not salient features of the implementation of the small and technically simple projects I examine, although they could be important determinants of project completion in other contexts.
} 
the common form of inflated contract values or sub-standard quality (Olken 2007; World Bank 2011), contractors may actually have stronger incentives to complete projects in order to fully reap their excess rents.

Figure 1: Unfinished projects
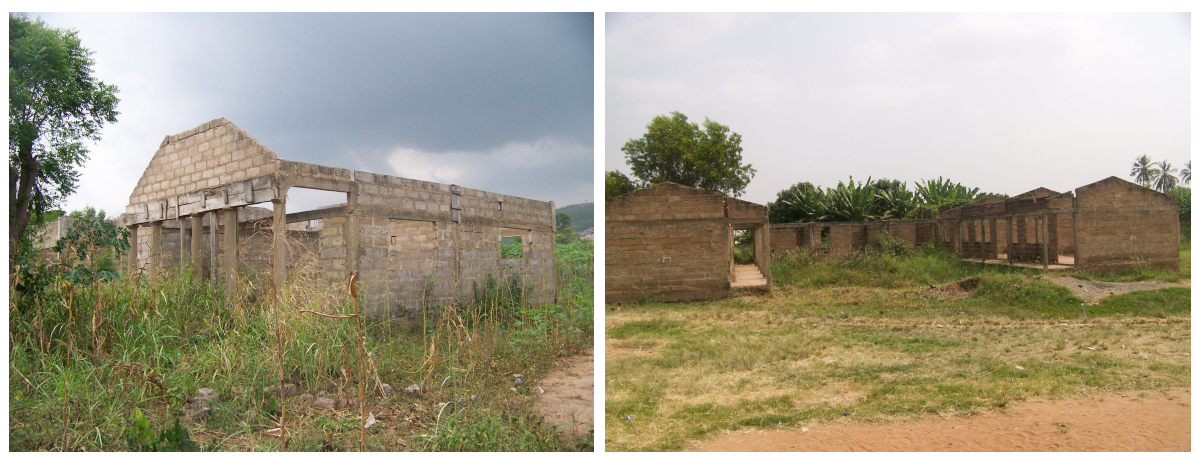

I develop an alternative theory of project non-completion as the dynamically inconsistent outcome of a collective choice process in contexts of limited resources, in which multiple political actors bargain over the distribution of a limited number of discrete, targeted projects. Building coalitions around a set of projects to be implemented in the current period requires intertemporal bargaining among these actors over future project distribution, but actors face credible commitment problems and so these bargains are inherently unstable, meaning that collective expenditure choices may not be dynamically consistent. Since project construction happens over a period of time, this time-inconsistency leads some projects to be interrupted mid-construction when collective expenditure priorities shift to new projects. The idea that collective choice over locally targeted projects among actors with commitment problems can lead to inefficient government expenditure has a long tradition in theory on public choice and legislative bargaining (Riker and Brams 1973; Weingast and Marshall 1988). However, it has received significantly less attention in developing country contexts, where research has focused almost exclusively on instrumental forms of public expenditure inefficiency.

I examine project completion empirically using an original dataset of over 
14,000 small local government projects in Ghana from 2011-13, which I compiled using administrative records that I collected, digitized, and coded. I estimate that approximately one-third of projects that start are never finished, consuming nearly 20 percent of all local government capital expenditure. ${ }^{3}$ Although not directly comparable in welfare terms, this estimate of the fiscal waste from noncompletion is of similar magnitude to Olken's (2007) estimate of resource loss from corruption in road building (24 percent) and Finan and Mazzocco's (2016) estimate of the percentage of public expenditure that is misallocated due to politically motivated distortions (26 percent). The social costs of non-completion are large: the money spent on non-completed projects by local governments alone would be enough to fully construct 667 additional three-room schools serving over 73,000 children, every year. ${ }^{4}$ Since school construction has been shown to lead to increased educational attainment and higher future wages in infrastructure-poor developing countries such as Ghana (Duflo 2001), this fiscal waste may have long-term developmental consequences. The political opportunity costs are also potentially substantial: delivering infrastructure projects has been shown to win votes for the incumbent in Ghanaian elections (Briggs 2012; Weghorst and Lindberg 2013; Harding 2015), citizens and media often refer to unfinished projects in negative performance evaluations of government (Ghana News Agency 2014), and elections in Ghana are often closely contested, with the 2008 presidential election being decided by just 40,586 votes (Whitfield 2009).

I derive and test observable implications of the corruption, clientelism, and collective choice theories of non-completion in the context of decentralized public good provision in Ghana. I overcome the endogeneity concerns that plague much of the empirical distributive politics literature (Larcinese, Snyder, and Testa 2012) by exploiting the fact that the same types of projects are delivered in the same districts and communities by the same local politicians, bureaucrats,

\footnotetext{
${ }^{3}$ Since I am only able to directly observe projects during this three-year window, estimating the percentage of projects that are ever completed requires some extrapolation (see section and Appendix E), and this percentage could be higher or lower during different time periods.

${ }^{4}$ Based on an average class size of 36.6, as reported in the World Bank's EdStats database for 2011 .
} 
and contractors, but funded through two different intergovernmental transfer mechanisms. These transfers are similar in design and implementation, except that one has an exogenously imposed funding rule that places districts at risk of losing future transfers if they fail to complete ongoing projects before starting new ones. Consistent with the predictions of the collective choice theory, this rule has a large effect in districts whose partisan composition is likely to make efficient collective choice difficult and a much weaker effect elsewhere. I further support this result by showing that central government projects are unaffected by district partisan composition, by addressing concerns about endogenous project selection using Oster's (forthcoming) coefficient stability approach, and through extensive robustness checks. I also find considerable evidence that is inconsistent with either corruption or clientelism being significant causes of project non-completion.

These findings on the extent and causes of project non-completion contribute to the broader literature on government expenditure inefficiency in several ways. The emphasis on the non-instrumentality of much expenditure inefficiency connects with Bandiera, Prat, and Valletti's (2009) distinction between active waste (which creates utility for the decision-maker) and passive waste (which does not), and their finding that the latter is quantitatively more important in procurement in Italy. While recent literature on developing countries has emphasized ways in which an agent might actively distort expenditure for private gain, whether through corruption or clientelism, expenditure decisions are arguably made through formal or informal collective choice processes at least as often as they are made by a unitary agent acting strategically. This is consistent with recent empirical studies by Hodler and Raschky (2014) and Burgess et al (2015), which find that greater constraints on the executive are associated with reduced ethnic favoritism in public good provision. Whereas these papers examine the effects of institutional change over time on public good provision, I demonstrate that different institutional rules can lead to different (and significantly improved) outcomes even when applied simultaneously to the same set of 
politicians and bureaucrats. The idea that institutions can mediate the workings of distributive politics parallels a similar literature on administrative agencies in US politics (Bertelli and Grose 2009). These findings also provide the first project-level evidence that the source of public funds matters for expenditure outcomes (Gadenne 2015).

Viewing project allocation and implementation as distinct, but not independent, processes has significant methodological and theoretical implications for future studies of public good provision. Numerous empirical studies of distributive politics in developing countries measure politicians' revealed tactical targeting strategies using either input-based measures of expenditure allocation (e.g. Keefer and Khemani 2009; Banful 2011) or output- or outcome-based measures of access or service quality (e.g. Franck and Rainer 2012; Kramon and Posner 2013). ${ }^{5}$ However, these measures are only equivalent if the determinants of project implementation are unrelated to the determinants of project distribution, which this study suggests may not always be the case. Policy implementation can thus have distributive causes and consequences, yet the implementation of distributive policies has been largely overlooked in theory and empirics alike.

More broadly, this study provides a link between micro-level studies of public good provision and the more abstract theoretical literature on institutions, states, and development. In particular, this study's empirical finding that institutions can improve efficiency by helping political actors collectively overcome credible commitment problems to resolve distributive conflicts is also a central idea in theories of institutions (Ostrom 1990) and the long-term development of state capacity (Acemoglu, Johnson, and Robinson 2005; Besley and Persson 2011). While the impact of institutions on development and state capacity has thus far been empirically examined mainly through longitudinal and crosscountry or -region studies, this article shows that specific institutional rules can

\footnotetext{
${ }^{5}$ Burgess et al (2015) use both an input-based measure of expenditure and an output-based measure of physical completion as alternative dependent variables, but do not investigate the discrepancy between them.
} 
play a similar role even within a single polity at a single point in time.

\section{Background: decentralized public good provision in Ghana}

The provision of local public goods is highly salient in both local (Ghana News Agency 2015) and national (Joy News 2014) politics in Ghana, and voters have been shown to reward the delivery of visible public goods (Briggs 2012; Weghorst and Lindberg 2013; Harding 2015). Yet voters and politicians alike frequently complain about projects being abandoned mid-construction. Unfinished projects are widely reported on by the media (Ghana News Agency 2014), with even Parliament (Citi FM 2014) and the President (Joy News 2014) complaining about non-completion. National elections are closely contested by two dominant parties, the National Democratic Congress (NDC, which won elections in 2008 and 2012 and was in power throughout this paper's study period) and the National Patriotic Party (NPP). The President is elected by national popular vote, so there is a strong incentive for the incumbent to deliver public goods in order to win votes across all districts. ${ }^{6}$

The responsibility for actually delivering many of these local public goods rests with local governments, since Ghana has decentralized responsibility for delivering a range of public amenities such as schools for primary education, sanitation, primary care clinics, marketplaces, and housing and offices for district staff. While districts are statutorily restricted to relatively small projects, total local government expenditure on capital projects is nonetheless substantial: GHS 317 million (equivalent to just over US $\$ 135$ million) in 2013, or 42.5 percent of their total revenue. ${ }^{7}$

\footnotetext{
${ }^{6}$ For example, prior to the 2016 election the incumbent launched its "Operation 1 Million Votes" campaign in the opposition stronghold Ashanti Region seeking to showcase its infrastructural achievements in the region in order to increase its vote totals (Daily Graphic 2015). I am grateful to Similarly, senior Local Government Service Secretariat (LGSS) officials report that local governments also sometimes target opposition areas with projects in a bid to win votes (Focus group, Accra, 21 November 2016).

${ }^{7}$ Author's calculations from Ministry of Local Government and Rural Development budget
} 
All districts are headed by a District Chief Executive (DCE) who is appointed by the President and presides over a directly elected district assembly, in which 70 percent of members are elected from geographically defined singlemember electoral areas and 30 percent are appointed by the President. ${ }^{8}$ DCEs do not have a fixed term and so would expect to serve until their party loses power or they are removed. Although district assembly elections are formally non-partisan, district assemblies and DCEs are widely perceived in Ghana as politicized, partisan actors. ${ }^{9}$ Assembly members are elected to four-year terms in elections that occur simultaneously nationwide; these took place in 2010, so the composition of assemblies was constant throughout this paper's study period of 2011-2013. District bureaucracies are composed of professional public servants, and the hiring and transfer of personnel is decided centrally.

Project selection is voted on in an annual budgeting process by assembly members and the DCE. The process begins with the District Planning and Coordinating Unit (DPCU), comprised of bureaucrats, which draws up a preliminary list of projects that then goes to the Executive Committee of the assembly for review and amendment. ${ }^{10}$ The Executive Committee is chaired by the DCE, and membership is decided jointly by the DCE and the Presiding Member of the assembly, who is elected by assembly members. The Executive Committee then puts a project proposal to the full assembly, which debates the list, suggests priority projects, and ultimately approves the list as part of the final budget. In practice, however, political negotiations over expenditure priorities are ongoing

data. The Public Procurement Act (2003, Act 663) fixes this threshold at GHS 200,000 (approximately USD 85,000). Calculations based on an exchange rate of USD $1=$ GHS 2.35 at 31 December, 2013.

${ }^{8}$ Depending on their size, Ghana's local government units are classified as district, municipal, and metropolitan assemblies. These legal and administrative distinctions are not relevant for this study, so for brevity I refer generically to districts and DCEs.

${ }^{9}$ Political parties often lend informal support to candidates during district assembly elections (GNA 2015), DCEs are accused of unduly politicizing their roles (Today 2015), and a nationwide study by Ghana's National Commission on Civic Education found that 68.6 percent of respondents believed that district assemblies were partisan in their operation (NCCE 2015).

${ }^{10}$ The process varies somewhat across districts. In particular, in some districts the Works Committee also plays an important role in feeding project proposals into the Executive Committee (Focus group with four senior LGSS officials, Accra, 21 November 2016). 
throughout the year, as plans and budgets are often not strictly implemented. ${ }^{11}$ These ongoing negotiations occur through both formal and informal means: the assembly itself meets three to four times throughout the year to receive an update on project progress and express their priorities, and may make mid-year changes to the plan and budget; and informal lobbying and protests by assembly members, other local elites, and communities in an attempt to influence expenditure decisions are common. ${ }^{12}$ Although DCEs are not formally downwardly accountable to the assembly, they nonetheless actively seek to maintain their popularity in districts as persistent protests can lead to their removal by the President. While DCEs may be the most powerful individual actors in project selection and expenditure decisions, both formally and informally these decisions are the products not just of the executive's tactical targeting choices, but also of a collective choice process that includes other influential district-level actors.

These choices are made in a context where demand for public goods is great, but resources are scarce. For example, Kwabre East District Assembly spent GHS 1.36 million on capital projects in 2013 (just above the national median), and was comprised of 42 geographically distinct settlements represented by 31 elected assembly members. In the same year, the mean cost for a six-room classroom block (the modal project type) was GHS 169,909. Even if the district spent its infrastructure budget entirely on classroom blocks, it could still only deliver eight of them within the year - roughly two-thirds of its assembly members and over four-fifths of its communities would not receive anything.

Yet Kwabre East, as with many other districts, spends these scarce resources in somewhat puzzling ways. In December 2010, for instance, the Assembly be-

\footnotetext{
${ }^{11}$ In a report on districts' project delivery, the Ghana Audit Service wrote: "The need for an Annual Action Plan to guide the implementation of the assemblies' programmes seems to be well-understood since virtually all the assemblies prepared action plans each year. However...[t]hey also did not show commitment to carry through their own plans by implementing the action plan thereby executing projects outside the action plans." (2016a, 16)

${ }^{12}$ For example, in Adansi South District angry residents burned the DCE's car in protest against his failure to deliver promised infrastructure projects to their communities (Ghanaweb 2016). Similarly, in a focus group senior LGSS officials stated that real or perceived reallocations of projects or resources from one community to another often lead to protests (Accra, 21 November 2016)
} 
gan construction of a six-room school block in the community of Aboaso that was expected to be complete within seven months. By the end of 2011 the construction had only reached the lintel level, however, and by the end of 2013 the project was still not complete despite the expenditure of GHS 50,500. The non-completion was not due to the lack of the GHS 79,164 it would have taken to complete the project: between the commencement of the Aboaso school and the end of 2013, the District Assembly spent over GHS 6 million on other infrastructure projects in the district, including starting nine new schools in other communities (of which it completed four). Similarly, the District Assembly started a weaving center in the community of Bamang in July 2009 and construction proceeded to the lintel level, but then no further funds were spent on the project and by 2013 the center still remained unfinished. Meanwhile, a different weaving center that had been started in another community after the Bamang center was completed promptly in 2011. This apparent inconsistency of priorities is a source of great frustration in Ghana among citizens and public servants alike, with the Ghana Audit Service making some version of the recommendation "that management of the Assemblies should endeavour to complete these projects before embarking on new ones" no fewer than six times in their 2013 audit report alone $(2014,20)$.

Districts' capital expenditures are funded primarily through intergovernmental transfers, as is common for local governments in developing countries (Gadenne and Singhal 2014). The two largest transfers are the District Assemblies Common Fund (DACF) and District Development Facility (DDF), both of which are periodic, lump sum, formula-based transfers to districts (similar to block grants in a federal system). ${ }^{13}$ The DACF is funded entirely by the central

\footnotetext{
${ }^{13}$ The DACF allocation formula is set each year by Parliament. While there is evidence that this formula has previously been manipulated to target funds to favored constituencies (Banful 2011), the magnitude of the effect is small and in any case should affect the absolute number of projects completed by districts, not the completion rate. The DDF allocation formula is based in part on an annual assessment of compliance with statutory regulations and administrative processes. Districts that perform better receive incrementally higher allocations, while districts that do not meet the minimum requirements do not receive funds for investment in that year's allocation. However, failure to meet minimum requirements has been rare after first year (prior to this sample) and the disbursements are made with a two-year lag from the assessment year, and as with the DACF any cross-district differences in quantity
} 
government, while the DDF is funded by a multi-donor pool with the central government also contributing 30 percent co-financing. (For ease of exposition, I will refer to DACF projects as "government-funded" and DDF projects as "donor-funded" henceforth.) Funds are transferred to district governments as a lump sum (i.e. they are not earmarked for specific projects or kept in separate accounts), so districts can prioritize and reallocate funds across projects. Whereas there are no administrative restrictions with respect to expenditure allocation across government-funded projects, under the donor-funded transfer districts are required to budget to complete existing projects before starting new ones. Otherwise, the two fund sources are operationally almost identical: in both cases project selection, procurement, and implementation are entirely conducted at the district level, by the same politicians and bureaucrats and through the same planning and budgeting process. Both are restricted to spending on capital investments rather than recurrent expenditures or private transfers, both are financially audited by the same central government auditors as part of the routine annual district audit process, and both are administered by small central government secretariats to which annual budgets and reports are submitted but which play no direct role in implementation.

While my primary focus is on district-level projects funded by these two intergovernmental transfers, I also examine a third major source of project funding, the Ghana Education Trust Fund ("centralized projects" henceforth), under which districts propose a list of projects from which a central government committee selects some to fund. Unlike the government- and donor-funded transfers, for centralized projects resources are not transferred directly to districts but are used centrally to pay contractors directly for work done in the districts.

of funds received should affect the level rather than rate of project completion. For both fund sources, funds are disbursed to all districts simultaneously so delays in disbursements affect all districts equally, and there is no evidence of any differential delay or manipulation of release timing. During my study period of 2011-13, there was no statistically significant correlation between the ruling party's vote share in a district and districts' revenue outturns (calculated as actual revenue divided by budgeted revenue), either for these intergovernmental transfers or total district revenue. 


\section{Unfinished projects as dynamically inconsistent collective choice}

This section presents a theory of project selection and implementation as collective choice, and sets out the observable implications of this theory in the context of decentralized public good provision in Ghana. I then discuss two alternative political economy-related explanations - corruption and clientelism - and their observable implications.

\section{Collective choice and project delivery}

While theories of distributive politics in developing countries have largely viewed expenditure decisions as the tactical choices of a unitary incumbent (Golden and Min 2013), in many contexts expenditure choices are made not by a unitary incumbent but by a group of political actors who have different distributive preferences. The canonical scenario is a legislature that must collectively select a set of projects that each deliver benefits to only one constituency. No legislator has an incentive to support a project in any other constituency, but each needs the support of others in order to gain majority approval of their own project, and so legislators must assemble coalitions by agreeing to vote for each other's projects. This is often referred to as "logrolling" over pork-barrel projects. Since not all projects can be implemented simultaneously and not all votes occur simultaneously - non-contemporaneous benefit flows and non-simultaneous exchange, in Weingast and Marshall's (1988) terms - forming vote-trading coalitions requires intertemporal bargaining among legislators. But these intertemporal bargains - vote for my project this year, and I will vote for your project next year are difficult to maintain, since legislators who have just received a project have an incentive to renege on their promise ex post. Knowing this, non-recipient legislators have little incentive to sacrifice their own immediate self-interest (receiving a project in their constituency) in order to support another legislator's project. These commitment failures make coalitions inherently unstable, as any 
structure of actor preferences that enables bargaining also enables voting cycles, making any existing coalition vulnerable to an alternative proposal (Riker and Brams 1973).

Political bargaining over projects in developing country contexts such as Ghana's local governments is typically not as formalized as logrolling in the US Congress, given the importance of informal politics and the relative weakness of legislatures, and may have de facto decision rules that are more complex or ambiguous than a simple majority vote. However, the project selection and delivery process in Ghana shares the key features of logrolling: spatially-targeted projects that deliver concentrated benefits to one political actor but few or no benefits to other actors; the necessity of nonetheless gathering some degree of support from non-recipient actors; and the time-inconsistency and thus instability inherent in the resulting intertemporal bargains. Senior Local Government Service officials also confirm the existence of these dynamics: while individual assembly members are primarily interested in projects in their own areas, formal and informal vote trading does occur as members seek broader support for their projects, and resources that had been allocated to one community are often reallocated later, leading to protests from the community. ${ }^{14}$

While project implementation (as distinct from selection) is not a feature of existing formal models of collective choice, it is straightforward to see how the instability of collective expenditure priorities could affect development projects that are not instantaneously implemented. As Figure 2 illustrates, the technical and contractual process of constructing even small projects involves not just an initial phase of project selection and budgeting, but also an iterated process of construction (by the contractor) followed by payment (by the government) throughout the life of a project. A six-room school in Ghana, for example, has a median expected project duration of five months and may be divided into five payment tranches, the non-payment of any of which can lead the contractor to

\footnotetext{
${ }^{14}$ Such protests occur in both opposition- and government-supporting communities. Focus group with four senior Local Government Service Secretariat officials, Accra, 21 November 2016.
} 
stop work until payment is made. Since each disbursement on a project takes funds away from other potential projects, each payment tranche effectively requires a reaffirmation of collective expenditure priorities. The more unstable these collective priorities are, the more likely it is that a project will be interrupted with no guarantee when (or if) its completion will once again become a collective priority. The effect of this political instability is aggravated by technical and contractual characteristics of infrastructure projects: mid-project delays increase the cost of completing the project due to interest costs, physical decay in exposed works, and eventual relocation of the contractor's staff and plant. ${ }^{15}$ Since the contract sums of small development projects are typically not indexed to inflation or exchange rates, these cost increases can render further work on contracts unprofitable for contractors after even relatively short delays.

Figure 2: Stylized timeline of a small infrastructure project

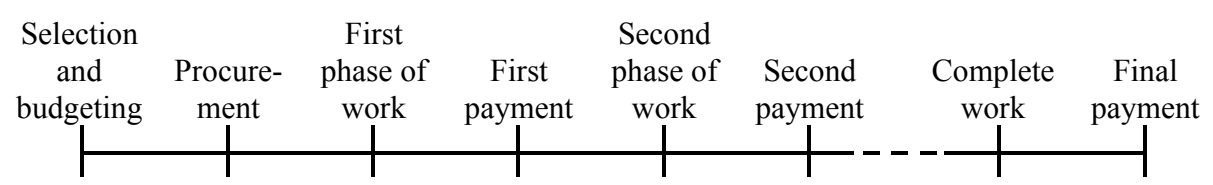

While novel to the political economy literature, the idea that unstable political support coalitions can affect project implementation features prominently in the qualitative policy implementation literature within public administration. For example, Pressman and Wildavsky note in their classic study of urban development projects in Oakland that "Agreements [among project stake-

\footnotetext{
${ }^{15}$ For example, Flyvbjerg, Holm, and Buhl (2004) estimate that each year of delay on transportation projects in OECD countries is associated with a 4.6 percent cost increase; in developing countries with higher inflation and interest rates and weaker legal systems, this figure would presumably be even larger. The Ghana Audit Service has also noted that "[d] elay in project execution eventually results in additional cost as prices of building materials continue to rise" $(2014,95)$. The cost of mid-project interruptions also explains why one standard response to coalition instability - the formation of universal or oversized coalitions (Weingast, Shepsle, and Johnsen 1981) - is an inadequate solution. Since projects (unlike transfers or budget allocations) are non-fungible there is a limit to which they can be subdivided to spread benefits more widely, and simultaneous implementation of too many projects necessarily leads some to be interrupted.
} 
holders] were reached, eroded, and remade. The frequent calls for coordination... reflected the inability of the machinery for implementation to move fast enough to capture the agreements while they lasted" (1984 [1973], 92). Similarly, political actors in Ghana express concern that the government's ability to efficiently provide public goods is undermined by its inability to simultaneously satisfy all the distributive demands on it. This is perhaps most clearly illustrated in a speech by the President of Ghana, John Mahama:

\begin{abstract}
"We all have demands on government but we have to be moderate in these demands in order that we do not disrupt the budget and government expenditure... As the head of your family, you cannot provide all that your family needs at once... Alhassan needs a shoe, Fuseini needs a bicycle, your wife needs a new cloth, and your mother needs a refrigerator. You cannot provide all these at once and so what you have to do is to prioritize... The fact that government has not yet provided a certain development that was requested does not mean that government will not provide it." (TV3 Network 2015)
\end{abstract}

The President's invocation of a familial metaphor to explain the necessity of sequencing project delivery, and his pleading with voters for patience "in order that we do not disrupt the budget and government expenditure", concisely summarizes both the necessity and difficulty for politicians of intertemporal bargaining over the delivery of public goods, as well as the negative efficiency consequences of failing to maintain these agreements. District-level actors also express similar concerns about how distributive pressures can undermine project execution. At a public hearing about a project audit, the bureaucratic head of Sekyere South district explained that the district bureaucracy "implements recommendations from the General Assembly. They have reduced projects but the citizens keep demanding projects...They [the General Assembly] try to prioritise but it is not easy to do so" (Ghana Audit Service 2016b, 68). A senior Audit Service official involved in project audits explained the consequences of having 
to pay for the constant stream of new projects: "It's not shown that it's being taken from the budget, but what it means is that the other projects won't be completed. And unfortunately these districts, a lot of the projects that they start they don't complete." 16

\section{Observable implications}

These collective choice dynamics cannot be examined directly in my empirical case, as much of the bargaining is informal and there is no data on proceedings and voting in district assemblies in Ghana (as is the case with local-level governance in many developing countries). I instead identify the impact of collective choice failures indirectly, by making theoretical predictions about characteristics of districts and fund sources that are likely to make sustaining intertemporal bargains over project distribution more (less) challenging, and thus lower (raise) completion rates.

Legislative institutions such as committees that enable agenda-setting and facilitate enforcement through rewards or punishments are key to resolving problems of the durability and enforceability of legislative bargains (Weingast and Marshall 1988, Baron and Ferejohn 1989). In the Ghanaian context, the executive is more likely to be able to stabilize local project support coalitions in districts that are politically aligned with the ruling party, due to two asymmetries in the structure of district governance in Ghana: the DCE is always appointed by the President, regardless of district vote shares; and in every district 30 percent of assembly members are appointed by the President to at-large seats.

DCEs can use their powers of ex ante agenda-setting - through their control of the DPCU, their chairing of the powerful Executive Committee, and their influence on committee memberships - and ex post implementation of assembly decisions to try to ensure that started projects get finished. However, their incentives to do so are much stronger when these projects benefit the ruling party

\footnotetext{
${ }^{16}$ Telephone interview, senior officer in the Performance Audit division, 27 January, 2017.
} 
- projects which incumbent-leaning assemblies are more likely to have started in the first place. Since DCEs control many non-project aspects of expenditure, they can also use other side-payments to induce cooperation from assembly members. Not only are they likely to be more willing to do so with respect to members of their own party but they may also be better able to commit to doing so due to the availability of intra-party sanctioning mechanisms. The Presiding Member of the assembly can also help stabilize resource allocations through their committee appointment powers, but this power is likely to support the DCE's efforts when they are co-partisans and work at cross-purposes when they are not.

There is ample qualitative support for the idea that DCEs selectively use their formal and informal powers to coordinate with co-partisans on project delivery. Local Government Service officers confirm that DCEs and opposition assembly members often have different preferences on project locations, stating that "DCEs in opposition strongholds will have a fight" to agree on project locations with the assembly. ${ }^{17}$ Similarly, Nathan $(2016,8)$ quotes one NDC assembly member as explaining, "He's [the DCE] a government appointee and I'm also from the same government... He listens to the NDC assembly members more than the others. It's the norm", while in contrast an NPP assembly member lamented, "But then your project, you have to spend years chasing it before you get the money... I don't bother going to the [DCE's] office... because the [DCE] has his own agenda, his own political agenda... The other assemblymen will have finished their projects, and they'll be saying no money for you."

Likewise, whereas the electoral incentives and thus project distribution preferences of elected assembly members are divided between bringing projects to their own electoral area and supporting projects in other areas that would be electorally beneficial to their party, the incentives of the appointed assembly members are to support whatever projects will be electorally beneficial for the incumbent. This is consistent with qualitative accounts of appointed members'

\footnotetext{
${ }^{17}$ Focus group, Accra, 21 November 2016.
} 
partisan affiliations, with (for example) a former president of the National Association of Local Government Authorities of Ghana stating "about 95 percent of the appointees to the assembly by the President belong to the party of the President" (Citi FM 2016). Appointed assembly members can thus act as a stabilizing force for project support coalitions of elected members, but have stronger incentives to do so when these coalitions are comprised of members of their own party.

Project completion should therefore be positively correlated with the district's partisan alignment with the ruling party, which I proxy by the ruling party's vote share in the presidential election preceding the study period. ${ }^{18}$ However, a simple test of this prediction using cross-district variation in partisan vote shares and project completion could be biased due to the potential endogeneity of voting patterns and public good provision or to unobservable confounds more generally.

Instead, I exploit within-district variation in the completion of projects across different fund sources. As discussed above, the donor-funded transfer program's rule that districts must budget to finish ongoing projects before starting new ones makes donor-funded projects less vulnerable than government-funded projects to collective choice failures, by strengthening non-recipient assembly members' incentives to complete ongoing projects located outside their electoral area. The within-district difference between donor- and government-funded project completion rates should thus be an indicator of the impact of collective choice failures on project completion. ${ }^{19}$ This funding rule is likely to have

\footnotetext{
${ }^{18}$ District-level election results would provide a more precise proxy, but they are formally non-partisan. The effect of ruling party vote share could, in theory, be non-linear, if the opposition party is numerically dominant enough in some districts to form stable coalitions and also bargain effectively with the appointed DCE. However since only 70 percent of assembly members are elected, the opposition would need to win over 95 percent of elected assembly seats to reach the two-thirds threshold of the assembly that is necessary to revoke or block a DCE's appointment. In practice this is unlikely, since the opposition's maximum vote share in any district in the 2008 presidential elections was 88 percent.

${ }^{19}$ Even with perfect enforcement, this rule should reduce, but not necessarily eliminate, the incidence of such collective choice failures on project completion. In practice the monitoring and enforcement of the rule is also likely to be imperfect. The within-district difference between donor- and government-funded completion rates is therefore likely to understate the true effect of collective choice problems on non-completion.
} 
the strongest effect in districts that are politically aligned with the opposition party, where these collective choice failures are most acute.

The key observable implication of the collective choice theory is therefore that the completion rate of government-funded projects should increase in districts with higher ruling party vote share relative to the completion rate of donor-funded projects in the same district. Since this prediction relies on withinrather than across-district variation in completion rates, it is possible to control for the observable and unobservable characteristics of districts, as well as for the politicians and bureaucrats selecting and implementing the projects, thus eliminating concerns about endogeneity and unobservable district characteristics.

A further implication of the idea that the ruling party's vote share in a district is a proxy for district-level collective choice failures (rather than a characteristic on which the incumbent tactically targets completion) is that vote share should have no effect on the completion of centrally delivered projects in the district. The completion rate of centralized projects relative to the completion rate of donor-funded projects should therefore be unrelated to district ruling party vote share.

\section{Alternative explanations: corruption and clientelism}

There are two other plausible explanations for project non-completion, in which non-completion is a deliberate outcome rather than a collective choice failure. First, non-completion could be caused by a specific form of corruption: projects could be left incomplete if contracts were given to favored contractors who are paid for the work but placed under little pressure to complete it. This would enable the contractors to keep as profit or pay as kickbacks the cost savings from not completing the project. ${ }^{20}$

\footnotetext{
${ }^{20}$ Corruption in the form of aggregate diversion of funds (e.g. Reinikka and Svensson 2004), as opposed to project-specific embezzlement or kickbacks, seems less plausible as a driver of project non-completion. Even if a percentage of a district's total funds were diverted from the infrastructure budget, it is not clear why reelection-seeking incumbents would not spend the remainder on fully completing a smaller number of projects. Aggregate resource diversion should therefore reduce the absolute number of projects completed rather than the completion rate, especially when project funds are drawn from a general pool and are not
} 
While this type of corruption on the "quantity" margin - as opposed to the quality and price margins that the existing literature has focused on (Olken 2007; World Bank 2011) - has not previously been documented, it does have a clear empirical implication: financial expenditure on non-completed projects should be greater than the physical progress of construction on these projects. In effect, this test is analogous to Olken's (2007) well-known indicator of "missing expenditures", albeit where the "missing" expenditure is on the quantity rather than the quality margin. In contrast, an observable implication of the collective choice theory is that the "missing expenditures" measure described above should be negative, reflecting underpayment to contractors for work done, as projects are interrupted mid-construction by non-payment due to shifting collective expenditure priorities.

Second, non-completion could be the outcome of a clientelist strategy by the ruling party to use project completion decisions as a way to reward or punish voters. However, existing theories of clientelism as tactical targeting of voters overwhelmingly focus on the allocation of projects, not their completion, so on their own these theories do not explain why a government would choose to allocate its scarce resources to begin a project in a particular community, but then not finish it. This observation is not to challenge the prevalence of clientelism in project allocations or voting patterns in Ghana or elsewhere, on which there is a large and well-established literature (cf. Golden and Min 2013), but rather to distinguish theories of the distribution of projects (which is not my focus) from theories of the implementation of these projects conditional on them having been started (which is).

Nevertheless, one way in which clientelist dynamics could lead to project noncompletion is if politicians deliberately leave projects incomplete before elections

earmarked for specific projects, as is the case in my empirical setting. Similary, the explanation that unfinished projects are simply used by politicians as a way to direct private transfers to communities in the form of labor income seems implausible as a general explanation of project non-completion, as a politician could deliver the same private benefits by seeing a project through to completion and also reap the additional political benefits of having provided a useful local public good. Even if politicians were motivated solely by the pecuniary gains to private individuals from public projects, it is unclear why a politician would opt to only partially implement such a project when completing it would entail even more such payments. 
due to voters' inability to credibly commit to reward projects with votes. This alternative version of the clientelism theory builds on the logic underlying theories of clientelism as a two-way credibility problem (Robinson and Torvik 2005; Robinson and Verdier 2013). While project completion is not the focus of these models, the logic of two-way credibility problems - that politicians sometimes find it rational to make apparently inefficient public expenditure choices in order to "tie the continuation utility of a voter to their political success" (Robinson and Verdier 2013, 261) - could potentially be applicable to project completion. If credit-claiming dynamics make the incumbent more likely than a challenger to complete a project started by the incumbent, starting but not finishing a project would increase nearby voters' incentives to vote for the incumbent, and so immediately before an election incomplete projects may actually be more desirable from the incumbent's point of view than completed projects.

This clientelism-based theory of non-completion has several observable implications. First, project non-completion should vary significantly across the electoral cycle. Since Ghana held a presidential election in December 2012, the clientelism theory would imply a lower completion rate in the election year (2012) than in pre-election (2011) or post-election (2013) years. ${ }^{21}$ A second implication is that the degree of physical progress on started projects is likely to be low, since the project start itself is what creates the desired voting incentives (from the incumbent's point of view) and further expenditure on the project does not enhance these incentives. Third, and in contrast to the predictions of the collective choice theory, if the ruling party views project non-completion as an effective political strategy then the completion rate of centralized projects should mirror that of government-funded projects - i.e., should be positively correlated with ruling party vote share relative to donor-funded projects. ${ }^{22}$

\footnotetext{
${ }^{21}$ An alternative view of project completion as driven by electoral cycles would predict that politicians would instead try to complete projects in election years so that its completion is fresher in voters' memories. However, this would only explain why project completion was delayed until an election year, not why projects were left incomplete indefinitely.

${ }^{22}$ This last observable implication also applies to the idea that the ruling party might start but not finish projects as a way to punish opposition voters, which - though it would seem a puzzlingly costly form of punishment - cannot be dismissed a priori.
} 
Table 1: Observable implications of theories of non-completion

\begin{tabular}{|c|c|}
\hline Theory & Observable implications \\
\hline Collective choice & $\begin{array}{l}\text { - Completion rate of government-funded projects positively corre- } \\
\text { lated with district ruling party vote share, relative to completion } \\
\text { of donor-funded projects } \\
\text { - Completion rate of centralized projects uncorrelated with dis- } \\
\text { trict ruling party vote share, relative to completion of donor- } \\
\text { funded projects } \\
\text { - Non-completion associated with underpayment to contractors } \\
\text { relative to physical progress on the project }\end{array}$ \\
\hline Corruption & $\begin{array}{l}\text { - Non-completion associated with overpayment to contractors } \\
\text { relative to physical progress on the project, i.e. "missing } \\
\text { expenditures" }\end{array}$ \\
\hline Clientelism & $\begin{array}{l}\text { - Completion rates vary across electoral cycle; lower in } 2012 \text { than } \\
2011 \text { or } 2013 \\
\text { - Level of physical progress and expenditure on incomplete } \\
\text { projects typically low } \\
\text { - Completion rate of centralized projects positively correlated } \\
\text { with district ruling party vote share, relative to completion of } \\
\text { donor-funded projects }\end{array}$ \\
\hline
\end{tabular}

Finally, there could also be other causes of project non-completion that are outside the scope of this paper, either because they are not directly related to political economy dynamics or because they are not relevant in my empirical context. Examples of the former could include the competence of bureaucrats and contractors, geographical or economy characteristics of communities, district budget sizes, or simple bureaucratic turnover, which I am able to fully control for empirically and thus should not bias the analysis. Examples of factors that are not relevant in my context could include elections that lead to the incumbent's removal or severe economic shocks that lead to unanticipated fiscal contractions, although it is easy to see how these could also cause project non-completion in other contexts. I discuss the scope conditions of this paper's theoretical argument further in Section .

\section{Measuring and describing non-completion}

\section{Data}

To measure the completion of infrastructure projects, I collected, digitized, and coded all available district Annual Progress Reports (APRs) for the years 2011- 
13. These reports are written annually by each district's bureaucracy and submitted to the central government, and include a table listing basic information about projects that were ongoing or active during the calendar year (Appendix A). Altogether it was possible to locate 479 out of a potential 602 district-year APRs (79.6 percent), of which 407 (67.6 percent) had sufficient information to be entered into the database. ${ }^{23}$ After cleaning and removing non-infrastructure projects, this yielded a database of 14,246 project-year observations, which is the core dataset used in this study's analysis.

Figure 3: Project type by fund source

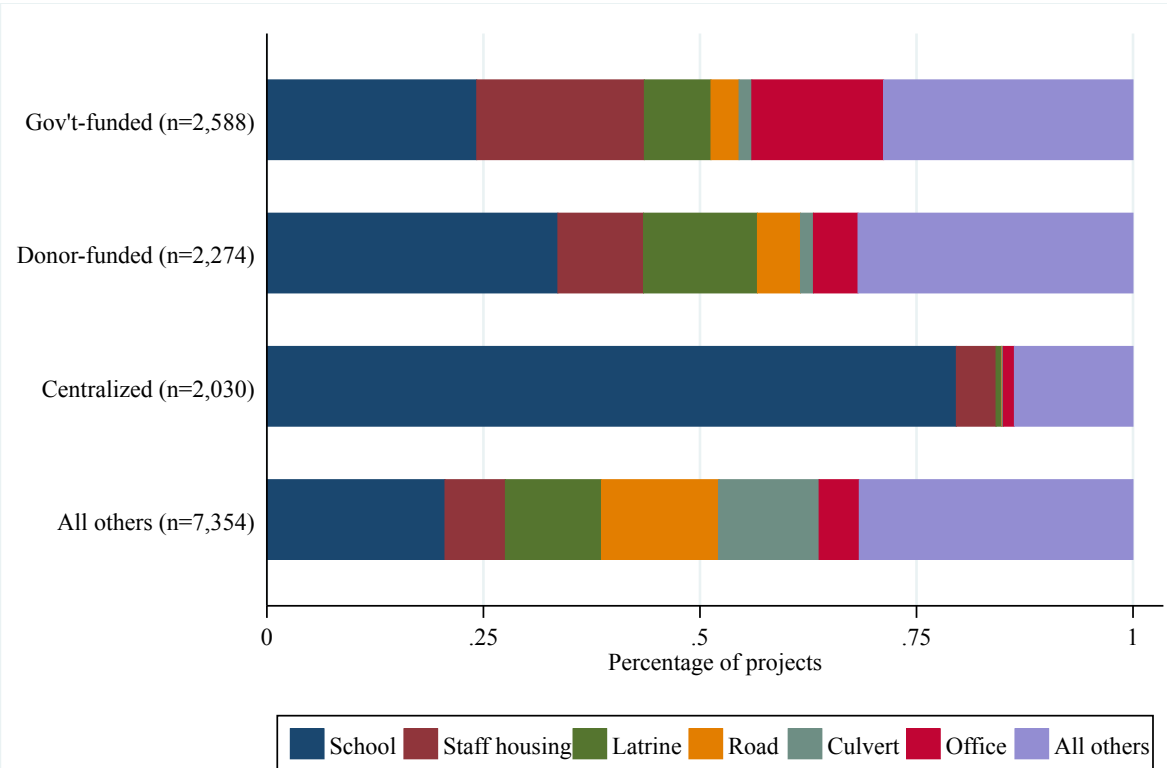

Note: See text and appendices for details of fund source and project type categories. Projects coded as multiple or missing types or fund sources included in 'All others'.

Tracking the progress of projects across years is challenging, since many projects do not have commencement dates reported, few districts make use of unique project identification numbers, data is censored before 2011 and after 2013, and many incomplete projects attrite out of the dataset. I use three alternative methods of linking project observations across years and take numerous steps to verify that the key results are not being driven by reporting

\footnotetext{
${ }^{23}$ Project completion rates and other district characteristics are balanced across districts' reporting completeness (Appendix B).
} 
bias, attrition, or double-counting; these are reported in Appendices D, E, and F. Most importantly for my empirical strategy, Appendix D shows that attrition is uncorrelated with project fund source and thus should not bias my main estimates.

All reports were manually double-entered into the database and variables were coded through text-matching from these strings, with manual disambiguation for key variables (see Appendix C). Projects were coded into 17 different basic "types", such as schools, clinics, and staff housing. The category "schools" was broken down into five sub-categories according to the number of classrooms, leaving a total of 22 project type categories. Project completion was coded for each observation as a binary variable by combining information from three raw variables. For instance, project completion was coded as 1 for values such as "COMPLETE", "100\%", or "INSTALLED AND IN USE", and 0 for values such as "ONGOING", "90\%", or "LINTEL LEVEL". ${ }^{24}$ I validated the accuracy of districts' completion reporting in several ways, including site visits, comparison against smaller datasets on project completion compiled through independent evaluation reports, interviews, and alternative government data sources, and found no evidence of systematic bias or misreporting of completion status in the reports (Appendix E).

In addition, for 140 districts I was also able to digitize District MediumTerm Development Plans. These were three-year plans written in late 2010 that included tables of planned development projects through 2013, and for the subset of districts with no missing APRs, I linked these planned projects (using the same procedure as linking across years of the APRs) to records of actual projects undertaken over the plan period from the APR dataset.

\footnotetext{
${ }^{24}$ I focus on the physical completion of projects because it directly corresponds to this paper's theoretical question about why a government would fail to complete a project it had started. However, it should be noted that my measure of project completion may differ from the actual utility communities derive from the projects: some completed projects may not be in use, and some projects nearing completion could be used by communities without being fully functional. Unfortunately I lack data on project use or user satisfaction to quantify this directly; doing so would be a useful extension for further research.
} 


\section{Extent, dynamics, and costs of non-completion}

Less than half of projects (45.8 percent) were finished within their first year of implementation, and even after three years 35.5 percent remained unfinished. ${ }^{25}$ These low completion rates were not due to long completion schedules: the median project had a scheduled duration of five months and 88.8 percent were scheduled to be complete within twelve months. The completion hazard rate decreases after the first year of a project: conditional on not being complete after one year, over half of projects see zero or near-zero physical progress in the subsequent year. ${ }^{26}$ A similar bifurcation of project outcomes is evident when examining delays: the median completed project was delayed by just one month, 81.0 percent were finished in less than twelve months, and just 10.7 percent were delayed by a year or more. The median incomplete project, however, is twelve months past its expected completion date - a 200 percent delay - and there is a long tail of over a quarter of incomplete projects that are more than two years past their planned completion date. These dynamics are consistent across project types, as Figure 4 shows for the three most common types.

While the availability of only three years of data makes it impossible to directly observe the eventual completion rate of projects left incomplete after three years, 99.5 percent of projects were scheduled to be completed within three years, and examining the completion dates of completed projects reveals that just 2.9 percent of completed projects took three years or more to complete. Assuming that the past distribution of project completion times reflects the time-to-completion distribution of projects started in a given year, extrapolating this rate out from the observed three-year completion rate implies that 33.5 percent of all projects are never completed. ${ }^{27}$ Of course, this estimate is based on the available three-year window of data that may or may not be representative

\footnotetext{
${ }^{25}$ Appendix D presents upper- and lower-bound estimates for these completion rates under alternative methodologies.

${ }^{26}$ Reported progress is precisely zero for 32.7 percent of projects and is 10 percent or less for 55.0 percent.

${ }^{27}$ If 64.5 percent of all projects were completed in three years or less and 2.9 percent of completed projects were completed in more than three years, then the percentage of projects ever completed is given by $0.645+0.029 *(0.645+0.029)=0.665$.
} 
Figure 4: Project completion

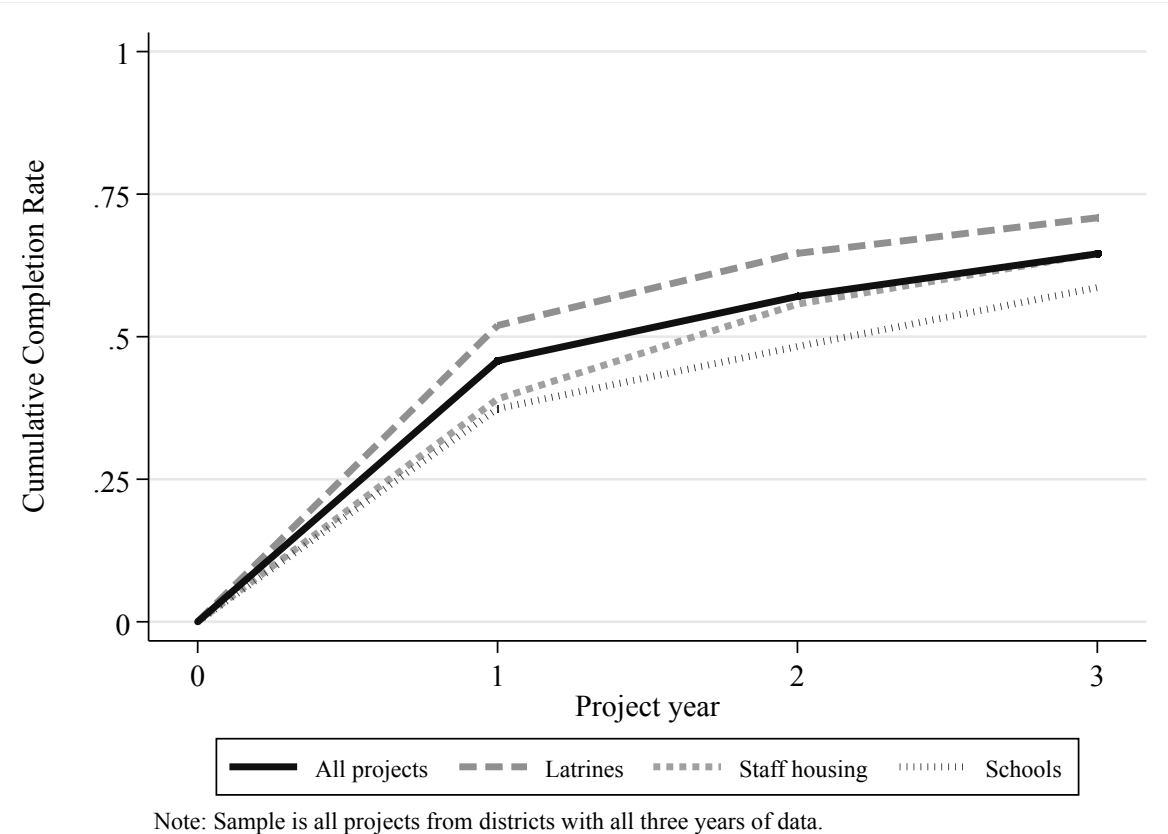

within Ghana, and thus project completion rates could be lower or higher in other time periods (or other countries).

A key observable implication of the clientelism theory of non-completion is that project completion rates should vary across the electoral cycle, and be lower in the election year, 2012. However, Figure 5 shows that there is no statistically significant variation in completion rates across years for government- or donorfunded projects. Completion rates are actually slightly higher in the election year for centralized projects for which the central government is responsible for implementation, suggesting that - if anything - the incumbent views completing projects just prior to elections as more electorally beneficial than leaving them unfinished. While electoral cycles could affect project completion in other contexts, particularly if the incumbent loses, in this case the phenomenon of unfinished projects is remarkably consistent across the electoral cycle.

Most unfinished projects have had a significant amount of work done on them: projects that remain unfinished after their third year average 64.9 percent 
Figure 5: Non-completion not driven by electoral cycle

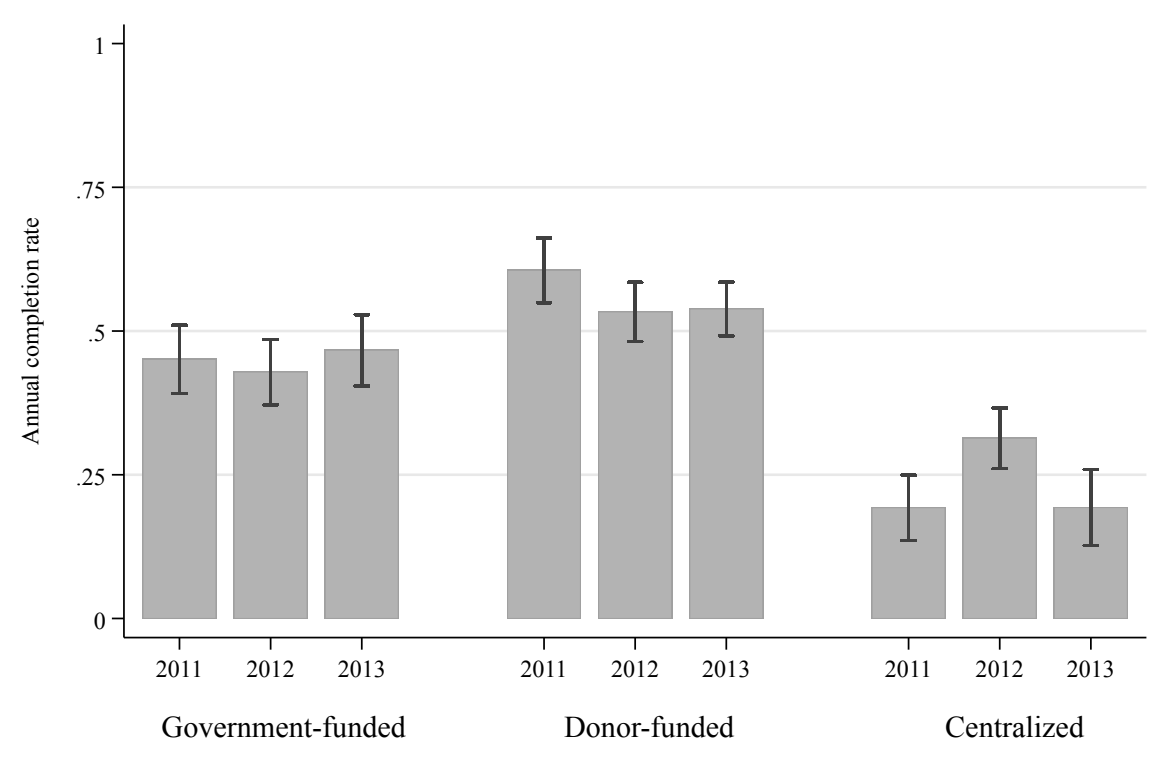

Note: Sample is all projects less than three years old (using project commencement date) within each fund source. 95\% confidence interval shown. Election in December 2012 .

physical completion and have seen 55.5 percent of the contract sum disbursed to the contractor. The heavy investment into unfinished projects contradicts a key observable implication of the clientelism explanation for non-completion, and also illustrates the fiscal and social costs of non-completion. If 33.5 percent of projects are never finished and expenditure on these averages 55.5 of the contract value, a back-of-the-envelope calculation suggests that 18.6 percent of total local government capital expenditure is spent on projects which will never be finished. Scaling this by the total capital expenditure of Ghana's local governments in 2013 of USD 135 million implies annual spending on neverto-be-completed projects of approximately USD 25.1 million. If this wasted expenditure were to be spent entirely on new three-room school buildings, it would be enough to fully construct 667 additional schools per year, so the social opportunity cost of non-completion is also substantial. ${ }^{28}$

To examine the observable implications of the corruption and collective

${ }^{28}$ Based on the mean contract sum of a new three-room classroom block in 2013 of GHS 88,389.09 (USD 37,612.38). 
choice theories of non-completion related to over- and under-payment of contractors, I construct a two-sided analog to Olken's (2007) missing expenditures measure by subtracting the percentage of physical construction that has been completed on a project from the percentage of the contract's value that has been paid by the district to the contractor. Positive values would be consistent with corruption in procurement - either through kickbacks or by selecting politically connected contractors who are paid but not put under pressure to finish projects - as a cause of non-completion, while negative values would be consistent with non-payment of contractors due to districts' unstable collective expenditure choices. Of course, positive values may also be due to factors other than corruption, such as project cost overruns, so this measure likely overstates the extent of corruption-related overpayment. While the relationship between these values need not be strictly linear, depending on the details of contracts and construction, for these small projects there are unlikely to be large discontinuities and for completed projects at least they should be equal. Appendix E discusses steps taken to validate these completion measures and shows that underpayment is not explained by normal time lags in processing payment.

Empirically, Figure 6 shows that underpayment of contractors is far more common than overpayment. For incomplete projects, underpayment by 10 percent or more is over three times more frequent than overpayment by 10 percent or more, and for completed projects underpayment is over sixteen times more common than overpayment. This is the opposite of what would be observed if corruption on projects were a significant driver of non-completion, but is consistent with project interruptions driven by unstable collective priorities: projects start, the contractor does part of the work, but at some point during construction the government's collective priorities shift and the government thus fails to make a payment for work done, so construction stops. ${ }^{29}$

The prevalence of underpayment is also consistent with qualitative accounts

\footnotetext{
${ }^{29}$ While an exact calculation of the cost to contractors of underpayment would require greater detail on construction costs and contracts than is available, a naïve estimate based on the 9.4 percentage point difference between average physical progress and payment disbursement would imply USD 12.7 million in annual underpayment to contractors.
} 
Figure 6: Missing expenditures and underpayment for completed work

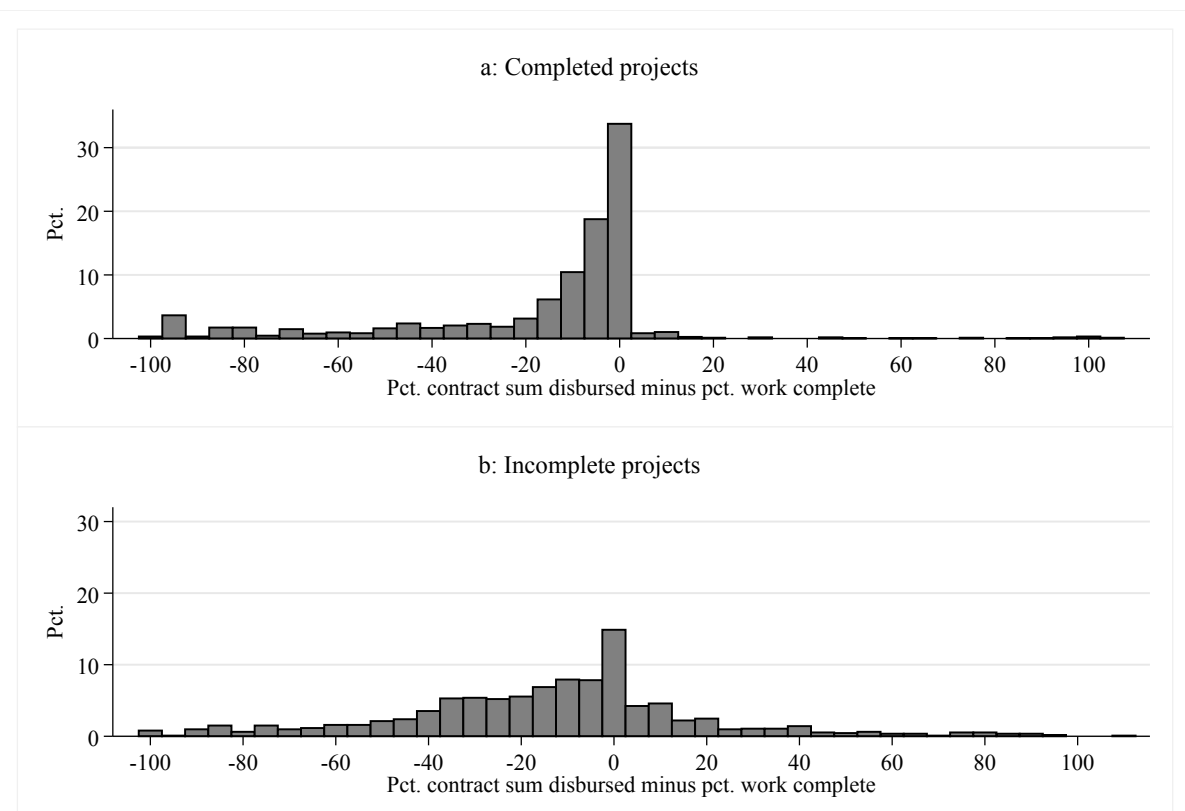

Note: Sample is 2,810 projects with data on contract sum, expenditure to date, and percent work completed.

of frequent complaints by contractors in Ghana about delayed- and non-payment by government (Abotsi 2013) and with the conclusions of central government auditors (Ghana Audit Service 2016a; see Appendix E). The link between districts' failure to pay contractors for work done and districts' shifting collective expenditure priorities has also been noted by auditors: a 2013 report of districts' spending of statutory funds criticized "the failure of the Assemblies to complete and pay for projects before embarking on new ones" and "recommended that management of the Assemblies should endeavour to discharge all obligations on time and also ensure completion and payment of ongoing projects before commencing new projects" (Ghana Audit Service 2014, 19). ${ }^{30}$

Finally, comparing planned projects to actual projects reveals a high degree

\footnotetext{
${ }^{30}$ This underpayment to contractors was not due to overall fiscal contractions or unexpected budget shortfalls: mean MMDA revenue grew by 8-9 percent annually from 2011-13, just slightly below the rate of inflation, so budget sizes were roughly stable in real terms. Furthermore, district-level revenue shortfalls do not seem to predict project completion rates in the data. District-year annual outturns of both total revenue and transfer revenue (calculated as actual revenue divided by budgeted revenue) are actually slightly negatively correlated with project completion rates, although these are not statistically significant at conventional levels. In any case, district-year fluctuations in revenue would be controlled for by the empirical specification used in Section below.
} 
of instability in district expenditure priorities. For the 39 districts with digitized medium-term plans and all three years of APR data, on average only 5.7 percent of projects that districts planned for the period were actually started, and only 3.8 percent of projects reported in the APR database could be identified in the plan for the period. ${ }^{31}$ These patterns are consistent with the premises of the collective choice theory that there is a large number of potential projects for which demand exists, and a great deal of temporal instability in which projects are recognized as collective priorities at any given moment.

\section{Analysis}

\section{Empirical strategy}

To examine the remaining observable implications of the collective choice and clientelism theories, I estimate a linear probability model (LPM) of the form:

$$
y_{i, j, k, t}=\boldsymbol{F} \boldsymbol{S}_{\boldsymbol{i}, \boldsymbol{j}, \boldsymbol{k}, \boldsymbol{t}} \boldsymbol{\beta}+\boldsymbol{F} \boldsymbol{S}_{\boldsymbol{i}, \boldsymbol{j}, \boldsymbol{k}, \boldsymbol{t}} * V_{k} * \boldsymbol{\tau}+\boldsymbol{P}_{\boldsymbol{i}, \boldsymbol{j}, \boldsymbol{k}, \boldsymbol{t}} \boldsymbol{\gamma}+\lambda_{j}+\theta_{k, t}+\varepsilon_{i, j, k, t}
$$

where $y_{i, j, k, t}$ is a binary indicator of completion of project $i$ of type $j$ in district $k$ and year $t,{ }^{32} \boldsymbol{F} \boldsymbol{S}_{\boldsymbol{i}, \boldsymbol{j}, \boldsymbol{k}, \boldsymbol{t}}$ is a vector of fund source indicator variables (governmentfunded and centralized, with donor-funded the omitted category), $V_{k}$ is the vote share in the district of the ruling party during the study period (the NDC) from the first round of the 2008 presidential elections ${ }^{33}, \boldsymbol{P}_{\boldsymbol{i}, \boldsymbol{j}, \boldsymbol{k}, \boldsymbol{t}}$ is a vector

\footnotetext{
${ }^{31} \mathrm{I}$ discuss attrition in linking in more detail in Appendix D, but even with a generous allowance for measurement error the correspondence between planned and actual projects would still be extremely low.

${ }^{32}$ Due to left and right censoring in the data and missing district-year observations, I am restricted to using as a dependent variable the annual completion rate - whether a projectyear observation was completed during that year - rather than whether the project was ever finished. I estimate the model using LPM due to the large number of fixed effects (thousands, in some specifications) which make estimation by logit or probit impractical and potentially biased. Appendix F provides evidence that the results are not driven by these modeling choices.

${ }^{33} V_{k}$ is not included by itself in the main model because it is time invariant and is thus absorbed by the district-year fixed effects. Ghana has a strongly two-party dominant system: the NDC and NPP were the top two parties in every constituency nationwide in the 2008 election and there were only a small number of constituencies where any third party obtained
} 
of project characteristics including construction type (i.e. new construction vs. maintenance or repair) and the number of years since project start, $\boldsymbol{\lambda}_{\boldsymbol{j}}$ is a vector of project type fixed effects, $\boldsymbol{\theta}_{\boldsymbol{k}, \boldsymbol{t}}$ is a vector of district-year fixed effects, $\varepsilon_{i, j, k, t}$ is an error term, and $\boldsymbol{\beta}, \boldsymbol{\gamma}$, and $\boldsymbol{\tau}$ are vectors of parameters to be estimated.

The parameters $\tau$ are of primary analytical interest. The parameter $\tau^{G o v^{\prime} t}$ represents the marginal effect of partisan vote share on government-funded project completion relative to the marginal effect on donor-funded project completion. A positive $\tau^{G o v^{\prime} t}$ would be consistent with the key observable implication of local-level collective choice failure in project completion. The identifying assumption is that any correlation between the within-district donorgovernment completion rate gap and the district's partisan alignment is driven only by the collective choice mechanism discussed above, so other factors could cause differences between the overall completion rates of donor- and governmentfunded projects without biasing my analysis so long as they are uncorrelated with district vote share $V_{k}$. Selection of projects into fund sources on unobservable project characteristics is the major concern with this assumption's validity, but I show below that such selection effects appear to generate, if anything, a downward bias on $\tau^{G o v^{\prime} t}$ and thus understate the true effect.

In turn, the parameter $\tau^{\text {Central }}$ shows the marginal effect of district partisan vote share on centralized project completion relative to its effect on donorfunded project completion. This interaction term functions similarly to a placebo test, in that if the effect $\tau^{G o v^{\prime} t}$ is driven by district-level collective choice failures, then $\tau^{\text {Central }}$ should be zero since these district-level collective choice processes should not impact project completion decisions by the central government. On the other hand, if $\tau^{\text {Central }}$ is also positive, then $\tau^{G o v^{\prime} t}$ could be reflecting a deliberate clientelistic strategy by the government which it is somehow constrained in employing with donor-funded projects.

a significant number of votes, so the ruling party vote share is almost perfectly correlated with other measures of partisan alignment, such as the winning margin or margin between the NDC and the NPP. 


\section{Interaction of fund source and partisan alignment}

I begin by estimating a simplified version of Equation 1 (Table 2, Column 1) on the sample of government- and donor-funded projects, with no fund source-vote share interaction term and with district-year random effects rather than fixed effects to enable the inclusion of the time-invariant variable $V_{k}$ (NDC vote share). As expected, the coefficient on the Government-funded dummy is negative government-funded projects have a conditional annual completion probability 10.9 percentage points lower than that of donor-funded projects ${ }^{34}$ - and the coefficient on NDC vote share is positive, although not statistically significant. This direct test of the effect of $N D C$ vote share is potentially misleading for two reasons, however: first, it assumes that this effect will be the same for both government- and donor-funded projects; and second, it does not fully control for district characteristics that could be correlated with both project completion and NDC vote share.

To address the first issue, Column 2 adds the Gov't-funded * NDC vote share interaction term. Consistent with the collective choice theory, the effect of $N D C$ vote share is entirely driven by government-funded projects: $\hat{\tau}^{G o v^{\prime} t}$ is positive and statistically significant $(p=0.031)$, while the main effect disappears entirely.

\footnotetext{
${ }^{34}$ This point estimate using the annual project completion is smaller than the three-year completion difference between donor- and government-funded projects of 14.5 percentage points. Using annual completion rather than eventual completion thus diminishes the magnitude of the estimated differences between fund sources, so this analysis if anything underestimates the true effects of other covariates on eventual project completion.
} 
Table 2: Interaction of project fund source and partisan vote share

\begin{tabular}{lccccccc}
\hline & $(1)$ & $(2)$ & $(3)$ & $(4)$ & $(5)$ & $(6)$ & $(7)$ \\
\hline Government-funded & -0.109 & -0.226 & -0.229 & -0.214 & -0.214 & -0.225 & -0.215 \\
& $(0.023)$ & $(0.060)$ & $(0.062)$ & $(0.059)$ & $(0.077)$ & $(0.078)$ & $(0.089)$ \\
NDC vote share & 0.111 & -0.028 & & & & & \\
& $(0.084)$ & $(0.115)$ & & & & & \\
Gov't-funded * NDC vote share & & 0.252 & 0.258 & 0.238 & 0.257 & 0.316 & 0.344 \\
& & $(0.116)$ & $(0.122)$ & $(0.115)$ & $(0.145)$ & $(0.149)$ & $(0.176)$ \\
Centralized & & & & -0.215 & -0.254 & -0.286 & -0.071 \\
& & & & $(0.071)$ & $(0.081)$ & $(0.099)$ & $(0.144)$ \\
Centralized * NDC vote share & & & & -0.069 & -0.016 & 0.099 & -0.137 \\
& & & & $(0.127)$ & $(0.152)$ & $(0.175)$ & $(0.250)$ \\
\hline District-Year random effects & Yes & Yes & & & & & \\
District-Year fixed effects & & & Yes & Yes & & & Yes \\
Community fixed effects & & & & & & & \\
Community-year fixed effects & & & & & & & Yes \\
Contractor fixed effects & 327 & 327 & 327 & 338 & & & 186 \\
District-Year groups & & & & & 2934 & & \\
Community groups & & & & & & 3650 & \\
Community-year groups & & & & & & \\
Contractor groups & 0.103 & 0.106 & 0.374 & 0.353 & 0.727 & 0.810 & 0.813 \\
$R^{2}$ & 4563 & 4563 & 4563 & 6460 & 5483 & 5483 & 4655 \\
$N$ &
\end{tabular}

Note: Dependent variable is project completion. All specifications include: fixed effects for 22 project types, with schools grouped by number of classrooms; construction type (construction or maintenance); and indicators 2008 is the ruling party's voteshare in the 2008 presidential elections in the district (or its antecedent district, for districts that split in 2012). Huber-White robust standard errors clustered by district-year in Columns 1-4, by contractor in Column 5 , by community in Column 6 , and by community-year in Column 7 . 
Column 3 presents the full model in Equation 1, using district-year fixed effects to fully control for all observable and unobservable district characteristics, both time-variant and -invariant. ${ }^{35}$ The coefficient $\hat{\tau}^{G o v^{\prime} t}$ remains positive and statistically significant $(p=0.035)$. The estimated effect is also economically important: a one standard-deviation increase in the ruling party's 2008 vote share in the district (16.9 percentage points, from a mean of 49.7 ) is associated with a 4.36 percentage point decrease in the donor-government completion rate gap. ${ }^{36}$ This is equivalent to closing 39.8 percent of the total completion gap between donor- and government-funded projects. In absolute terms, a new sixroom school in a district at the $5^{\text {th }}$ percentile of NDC vote share (corresponding to a strongly opposition-supporting district where the NDC received only 21.1 percent of the vote) would have an estimated annual completion probability of 49.7 percent if it were donor-funded (CI: 38.9-60.4) but just 32.4 percent if government-funded (CI: 22.4-42.4), a gap of 17.3 percentage points. In a district at the $95^{\text {th }}$ percentile of NDC vote share (88.9 percent), however, this gap disappears: the government-funded school would have a completion probability of 47.6 percent (CI: 36.1-59.1), almost identical to that of the donor-funded school (47.8 percent, CI: 34.6-60.9) ${ }^{37}$ This is strong evidence in support of the collective choice theory of non-completion: in districts where local political actors are almost uniformly aligned with the incumbent, the executive is better able to use its agenda-setting, implementation, and intra-party enforcement mechanisms to uphold intertemporal bargains on project sequencing and thus avoid leaving projects incomplete.

\footnotetext{
${ }^{35}$ This would include potential determinants of project completion such as the quality of, or turnover in, district-level bureaucrats and politicians, budget sizes, and other district geographic, economic, and political characteristics.

${ }^{36}$ I estimate the fixed effects models using the Stata command $x$ treg rather than areg, since areg calculates standard errors using an overly conservative degrees-of-freedom adjustment that is unnecessary when fixed effect groups are nested within clusters (Gormley and Matsa 2014). For comparison, re-estimating the Column 3 specification with areg produces a pvalue for $\hat{\tau}^{G o v^{\prime} t}$ of 0.042 . However, for each model I report the $R^{2}$ generated by the Stata command areg, since the $R^{2}$ generated by xtreg is for the demeaned dependent variable and thus considerably understates the explained variation when fixed effects are numerous and powerful, as in my context.

${ }^{37}$ These absolute estimates are based on the Column 2 specification without district-year fixed effects.
} 
Figure 7: Marginal effect of partisan alignment by fund source

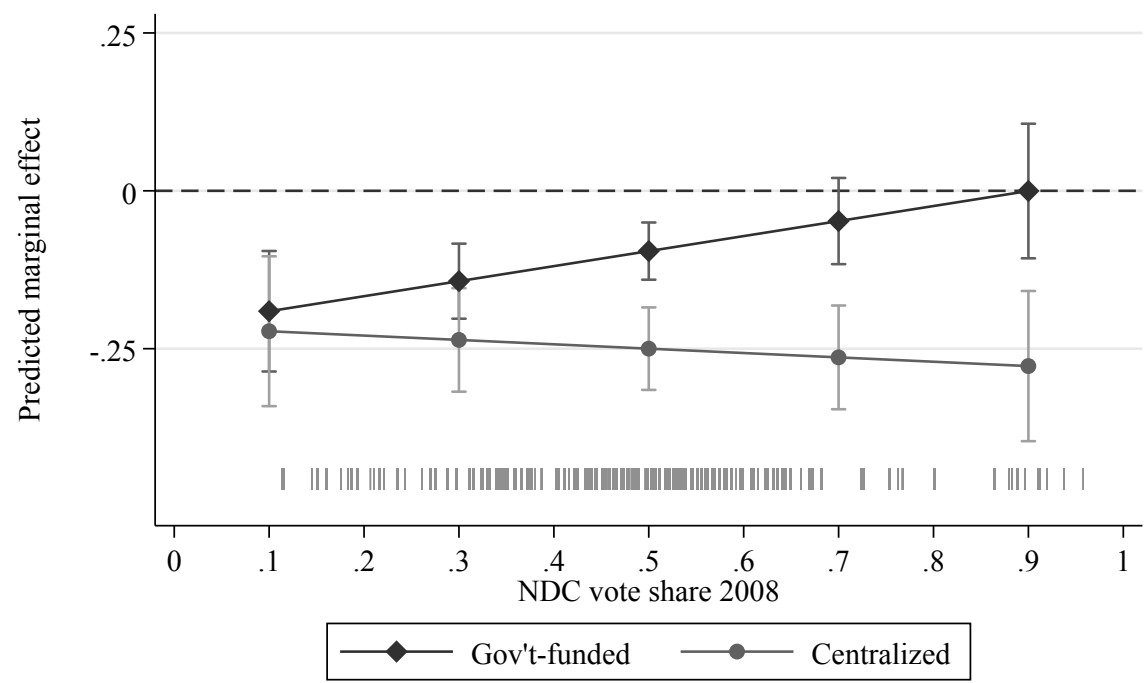

Note: Marginal effects of partisan alignment on predicted completion of government-funded and centralized projects are shown relative to its effect on donor-funded projects (dashed line at zero), with $95 \%$ confidence intervals. Based on Table 2, Column 4.

To further discriminate between the observable implications of the collective choice and clientelism theories, Column 4 adds centralized projects into the estimation sample and introduces the centralized dummy and interaction term. While $\hat{\tau}^{\text {Central }}$ is not significantly different than zero (indeed, is slightly negative), $\hat{\tau}^{G o v^{\prime} t}$ remains positive and significant, and the difference between the two coefficients is statistically significant $(p=0.017)$. This is inconsistent with the clientelism theory that government-funded project completion patterns reflect a deliberate policy of the incumbent either to leave projects unfinished in order to give voters an incentive to return them to office or to punish opposition voters. If the government thought this to be an effective political strategy, we would have expected that $N D C$ vote share should have a similar effect on centralized projects as it does on government-funded projects executed by districts. Instead, the markedly different effects are consistent with the collective choice theory that the incumbent is constrained in the completion of government-funded projects by local-level collective choice problems that are more difficult to resolve in 
opposition-leaning districts. The district-year fixed effects in this specification also exclude the possibility that the observed effects are driven by changes in districts' political leanings over the study period, which is further evidence that these results are not driven by clientelist dynamics of using project completion tactically to reward or punish voters. Figure 7 presents the marginal effects of $N D C$ vote share on the three fund sources graphically, with donor-funded projects as the baseline category represented by the dashed horizontal line at zero.

A further concern is that the relevant clientelist dynamics might operate not at the level of whole districts, but rather across communities within districts. For example, if within each district the government systematically allocated donor-funded projects to its core supporter communities and government-funded or centralized projects to opposition communities, and if donor-projects were more likely to be completed and projects in core supporter communities were also more likely to be completed, then the estimates of $\hat{\tau}^{G o v^{\prime} t}$ in Columns 1-4 could be biased upwards. To address this, Column 5 re-estimates Equation 1 with fixed effects for the 2,934 communities in which projects were executed, to control for all observable and unobservable characteristics of these communities, including partisan affiliations as well as other more general communitylevel determinants of project completion. Controlling for these community-level factors actually slightly increases the point estimate of $\hat{\tau}^{G o v^{\prime} t}$, although the statistical significance drops slightly $(p=0.077)$ due to an increase in standard errors. Column 6 pushes this even further by controlling for communityyear fixed effects, thus capturing any shifts over time in partisan affiliations that might affect project completion, leading to $\hat{\tau}^{G o v^{\prime} t}$ increasing even further and becoming more statistically significant $(p=.034)$. The continued significance of district-level partisan affiliation in explaining government-funded (but not donor-funded or centralized) project completion - even after controlling for time-variant community-specific determinants of project completion - is strong evidence that these results are driven not by clientelist strategies of using project 
completion as a reward or punishment, but rather by district characteristics that affect collective choice outcomes.

Finally, Column 7 adds contractor fixed effects, since $\hat{\tau}^{\text {Gov'}^{\prime} t}$ could be biased upward by contractor identity if the donor-government completion gap was driven by contractor quality and less able contractors were more likely to be selected in opposition-leaning districts. This specification takes advantage of the fact that some of the 2,592 contractors who implemented these projects did so in multiple districts and/or for multiple fund sources. The estimated $\hat{\tau}^{G o v^{\prime} t}$ actually increases slightly and remains statistically significant $(p=0.050)$. This provides further evidence that the observed patterns of project non-completion are not being driven by theories of corruption and clientelism that focus on rent-seeking behavior in procurement by politicians, bureaucrats, and politically connected contractors.

These results are robust to a wide range of alternative specifications and additional controls; Appendix F presents these specifications.

\section{Addressing endogenous selection into fund sources}

Even though the district-year, project type, community, and contractor fixed effects control for a wide range of observable and unobservable variables that could bias the analysis, one remaining concern is that communities may be sufficiently heterogeneous that projects could even be targeted (i.e., be locally excludable) within communities, for instance based on very local ethnic or partisan geography (Ichino and Nathan 2013). If projects are locally excludable and thus can be targeted based on within-community unobservable variation, this could potentially bias $\hat{\tau}^{\text {Gov't }^{\prime}}$ upwards if the extent of within-community selection of projects into fund sources was also positively correlated with the ruling party's vote share in the district.

Although I lack detailed geographic data with which to measure this withincommunity heterogeneity directly, I am able to gauge whether this bias could plausibly be driving $\hat{\tau}^{\text {Gov }^{\prime} t}$ using the coefficient stability approach developed by 
Table 3: Community fixed effects

\begin{tabular}{lcc}
\hline & $(1)$ & $(2)$ \\
\hline Government-funded & -0.243 & -0.214 \\
& $(0.061)$ & $(0.077)$ \\
Centralized & -0.247 & -0.254 \\
& $(0.076)$ & $(0.081)$ \\
Gov't-funded * NDC vote share & 0.263 & 0.257 \\
& $(0.118)$ & $(0.145)$ \\
Centralized * NDC vote share & -0.045 & -0.016 \\
& $(0.134)$ & $(0.152)$ \\
\hline District-Year fixed effects & Yes & \\
Community fixed effects & & Yes \\
District-Year groups & 288 & \\
Community groups & & 2934 \\
$R^{2}$ & 0.373 & 0.727 \\
$N$ & 5483 & 5483 \\
\hline
\end{tabular}

Note: Dependent variable is project completion. Sample is all projects with non-missing community name. All specifications include project type and characteristics as in Table 2. Year fixed effects included in Column 2. Huber-White robust standard errors clustered by district-year in Column 1 and community in Column 2.

Altonji, Elder, and Taber (2005) with corrections from Oster (forthcoming) and Gonzalez and Miguel (2015). Oster shows that, if selection on unobservables (such as within-community variation) is as strong as selection on observables (across-community variation), a bias-adjusted estimate of $\tau$ is:

$$
\tau^{*}=\tilde{\tau}-(\dot{\tau}-\tilde{\tau}) \frac{R_{\max }-\tilde{R}}{\tilde{R}-\dot{R}}
$$

where $\tilde{\tau}$ is the estimated coefficient from a regression including community fixed effects (Column 2) and $\tilde{R}$ is the $R^{2}$ from this regression, $\dot{\tau}$ is the estimated coefficient from the regression excluding community fixed effects (Column 1) and $\dot{R}$ is the $R^{2}$ from this regression, and $R_{\max }$ is the percentage of all variation in the dependent variable theoretically explainable by all possible observables and unobservables. Even under the most conservative case of $R_{\max }=1$ where within-community unobservables account for all remaining unexplained variation and there is no measurement error, calculating $\tau^{* G o v^{\prime} t}$ using Equation 2 and the estimates from Table 3 still generates a bias-adjusted coefficient of 
0.253. More intuitively, these estimates imply that the process of endogenous selection into fund sources on unobservable within-community variation would have to be 58 times stronger than the process of within-district selection across communities in order for the observed $\hat{\tau}^{G o v^{\prime} t}$ to be driven entirely by selection on unobservables. While a correlation between NDC vote share and the degree of endogenous selection of projects into fund sources cannot be ruled out, it seems implausible that selection on unobservables accounts for more than a tiny share of the differential effect of $N D C$ vote share on government-funded projects relative to donor-funded ones.

\section{Conclusion}

This article has: 1) provided the most comprehensive evidence to date on the extent and costs of development project non-completion in one country, Ghana; 2 ) argued that this phenomenon is best understood as the inefficient outcome of a dynamically inconsistent collective choice process among local political actors, rather than an instrumental outcome of corruption or clientelism; and 3) shown that the effects of these collective political failures are mediated by the fiscal institutions through which projects are delivered. I conclude by discussing some broader implications of these three contributions.

First, whereas recent literature on the political economy of public good provision has overwhelmingly focused on corruption as a cause of implementation failure, this article echoes Bandiera et al's (2009) emphasis on the non-instrumental nature of much expenditure efficiency. In contrast to Bandiera et al, though, I show that implementation failure can be caused by distributive pressures and have consequences for distributive outcomes. The view of implementation as potentially endogenous to distribution presents an opportunity for theory development, as well as a major methodological and measurement challenge: whereas empirical studies of distributive politics usually treat measures of the partisan, geographic, or ethnic incidence of public good inputs, outputs, and outcomes as 
interchangeable (mostly out of convenience), if implementation is endogenous to distribution then these associations will differ and thus be potentially biased measures of politicians' "true" targeting strategies.

Second, the insight that significant fiscal waste can arise due to the de jure and de facto collective nature of government expenditure decisions - rather than simply the private incentives of a powerful agent - has wide-ranging implications for research on the political economy of public good provision in developing countries. Whereas political economy theories of clientelism and distributive politics focus on the potentially distortionary impact of elections on the expenditure choices of an incumbent politican, these findings emphasize that much of the formal and informal politics of delivery actually takes place in between elections. Greater attention to the institutional and bureaucratic details of how and by which actor(s) expenditure decisions are actually made could shed light on these understudied dynamics, and - together with the endogeneity between distributive concerns and implementation - may help to explain the puzzling variation in public good provision patterns observed in the empirical distributive politics literature (Golden and Min 2013).

While the collective choice mechanism proposed in this paper seems most applicable to contexts of electoral competition and relatively scarce resources, it is likely to have broader relevance. Building coalitions of competing interest groups is a central aspect of politics in democracies and autocracies alike, and access to government expenditure is often the object of coalitions' formation as well as one of the main tools that can be used to sustain them. Similarly, most polities are characterized by limited budgets and excess demand for government expenditure. $^{38}$ Although my analysis has focused on physical infrastructure projects, the same mechanism could also apply to any non-physical types of expenditure whose implementation is not instantaneous. The strength of institu-

\footnotetext{
${ }^{38}$ The Senate testimony of a former head of Nigeria's Bureau of Public Procurement regarding the abandonment of 19,000 government projects provides suggestive evidence that the mechanism described in this article is not restricted to Ghana: "[He] told the lawmakers that abandonment of the projects occurred mainly because of non-payment for interim certificates for work done" (Vanguard 2016).
} 
tions that stabilize political coalitions or limit the impact of political instability on implementation processes seem likely to be key determinants of the extent to which these collective choice issues manifest in policy implementation across contexts.

Finally, these findings have important policy implications for government, donors, and aid. The extent of wasteful expenditure and the impact of fiscal institutions in improving project completion suggest that greater investment in expenditure monitoring and control in intergovernmental transfer systems can be an effective way to improve public good provision. Another implication is that donor involvement in project delivery in developing countries may be beneficial not only by contributing funds, but also by strengthening government delivery institutions, especially since it may be easier for donors to credibly commit to enforcing rules than the government. This is a largely unexplored area for research and policy design, and a new perspective on debates around aid effectiveness.

\section{References}

Abotsi, Pascal Kafu. 2013. "Contractors Blame Economic Hardship on Gov." The Chronicle, 18 September, 〈http://thechronicle.com.gh/contractors-blameeconomic-hardship-on-gov/ $\rangle$, accessed 8 April 2015.

Acemoglu, Daron, Simon Johnson, and James A. Robinson. 2005. "Institutions as a Fundamental Cause of Long-Run Growth." In Aghion, Philippe, and Steven N. Durlauf (eds), Handbook of Economic Growth, Volume 1A, 385-472.

Altonji, Joseph, Todd G. Elder, and Christopher E. Taber. 2005. "Selection on observed and unobserved variables: assessing the effectiveness of Catholic schools." Journal of Political Economy 113 (1): 151-184.

Bandiera, Oriana, Andrea Prat, and Tommaso Valletti. 2009. "Active and Passive Waste in Government Spending: Evidence from a Policy Experiment." 
American Economic Review 99(4): 1278-1308.

Banerjee, Abhijit, Rema Hanna and Sendhil Mullainathan. 2013. "Corruption". In Gibbons, Robert, and John Roberts (eds.) (2012), The Handbook of Organizational Economics, Princeton: Princeton University Press, 1109-1147.

Banful, Afua Branoah. 2011. "Do formula-based intergovernmental transfer mechanisms eliminate politically motivated targeting? Evidence from Ghana." Journal of Development Economics 96: 380-390.

Baron, David, and John Ferejohn. 1989. "Bargaining in Legislatures." American Political Science Review 83(4): 1181-1206.

Bertelli, Anthony, and Christian R. Grose. 2009. "Secretaries of Pork? A New Theory of Distributive Public Policy." Journal of Politics 71(3): 926-945.

Besley, Timothy, and Torsten Persson. 2011. Pillars of Prosperity: The Political Economics of Development Clusters. Princeton: Princeton University Press.

Briggs, Ryan C. 2012. "Electrifying the base? Aid and incumbent advantage in Ghana." Journal of Modern African Studies 50(4): 603-624.

Burgess, Robin, Remi Jedwab, Edward Miguel, Ameet Morjaria, and Gerard Padró i Miquel. 2015. "The Value of Democracy: Evidence from Road Building in Kenya." American Economic Review 105(6): 1817-1851.

Citi FM. 2014. "MMDAs to be forced to complete projects - PAC." 〈http:// citifmonline.com/2014/11/01/mmdas-to-be-forced-to-complete-projects-pac/ \#sthash.KBZMV5fB.dpbs〉, accessed 27 March, 2015.

Citi FM. 2016. "Assembly system outmoded; MMDCEs must be elected - Kyei Baffour." 〈http://citifmonline.com/2016/09/28/assemblies-must-go-partisanlocal-governance-expert/\#sthash.au08NvZf.dpuf), accessed 10 January, 2017.

Cox, Gary, and Mathew McCubbins. 1986. "Electoral Politics as a Redistributive Game." Journal of Politics 48(2): 370-389. 
Daily Graphic. 2015. "NDC to win one million votes in Ashanti." 〈http://www. graphic.com.gh/news/politics/ndc-to-win-one-million-votes-in-ashanti.html $\rangle$, accessed 23 January, 2017.

Dixit, Avinash, and John Londregan. 1996. "The Determinants of Success of Special Interests in Redistributive Politics." Journal of Politics 58(4): 11321155.

Duflo, Esther. 2001. "Schooling and Labor Market Consequences of School Construction in Indonesia: Evidence from an Unusual Policy Experiment." American Economic Review 91(4): 795-813.

Finan, Frederico, and Maurizio Mazzocco. 2016. "Electoral Incentives and the Allocation of Public Funds." NBER Working Paper 21859, January.

Flyvbjerg, Bent, Mette K. Skamris Holm, and Soren L. Buhl. 2004. "What Causes Cost Overrun in Transport Infrastructure Projects?" Transport Reviews: A Transnational Transdisciplinary Journal 24(1): 3-18.

Franck, Raphael, and Ilia Rainer. 2012. "Does the Leader's Ethnicity Matter? Ethnic Favoritism, Education, and Health in Sub-Saharan Africa." American Political Science Review 106(2): 294-325.

Gadenne, Lucie. 2015. "Tax Me, but Spend Wisely? Sources of Public Finance and Government Accountability.” Mimeo, June.

Ghana Audit Service. 2014. "Report of the Auditor-General on the Public Accounts of Ghana Ministries, Departments and Other Agencies (MDAs) for the Year Ended 31 December 2013." Accra, 1 September.

Ghana Audit Service. 2016a. "Consolidated Report of the Auditor-General on the 50 District Assemblies Audited under GSAM Project." Accra, August.

Ghana Audit Service. 2016b. "Report on the Dissemination of Audit Findings on the Infrastructure Audits Carried Out by Ghana Audit Service under the GSAM Programme." Accra, May. 
Ghana News Agency. 2014. "Ghana @ 50 Project left to rot." /http://www. ghananewsagency.org/print/75622〉, accessed 27 March, 2015.

Ghana News Agency. 2015. "Political Party Interference Marks Upcoming Assemblies' Elections - CODEO." 〈http://www.ghanaweb.com/GhanaHomePage/ NewsArchive/Political-party-interference-marks-upcoming-assemblies-electionsCODEO-376599〉, accessed 14 September, 2015.

Ghanaweb. 2016. "Angry youth burn MP's car over failed campaign promises." http://www.ghanaweb.com/GhanaHomePage/NewsArchive/Angry-youth-burnMP-s-car-over-failed-campaign-promises-446147, accessed 9 June, 2016.

Golden, Miriam, and Brian Min. 2013. "Distributive Politics around the World." Annual Review of Political Science 16: 73-99.

Gonzalez, Felipe, and Edward Miguel. 2015. "War and local collective action in Sierra Leone: A comment on the use of coefficient stability approaches." Journal of Public Economics 128: 30-33.

Gormley, Todd, and David Matsa. 2014. "Common Errors: How to (and Not to) Control for Unobserved Heterogeneity." Review of Financial Studies 27(2): 617-661.

Harding, Robin. 2015. "Attribution and Accountability: Voting for Roads in Ghana." World Politics 67(4): 656-689.

Hodler, Roland, and Paul Raschky. 2014. "Regional Favoritism." Quarterly Journal of Economics 129(2): 995-1033.

Ichino, Nahomi, and Noah Nathan. 2013. "Crossing the Line: Local Ethnic Geography and Voting in Ghana." American Political Science Review 107(2): 344-361.

Keefer, Philip. 2007. "Clientelism, Credibility, and the Policy Choices of Young Democracies." American Journal of Political Science 51(4): 804-821. 
Keefer Philip, and Stuti Khemani S. 2009. "When do legislators pass on pork? The role of political parties in determining legislator effort." American Political Science Review 103(1): 99-112.

Kramon, Eric, and Daniel Posner. 2013. "Who Benefits from Distributive Politics? How the Outcome One Studies Affects the Answer One Gets." Perspectives on Politics 11(2): 461-474.

Joy News. 2014. "President Mahama: I will continue all abandoned projects." 〈http://www.myjoyonline.com/news/2014/September-10th/president-mahamai-will-continue-all-abandoned-projects.php $\rangle$, accessed 25 March, 2015.

Larcinese, Valentino, James Snyder, and Cecilia Testa. 2012. "Testing Models of Distributive Politics using Exit Polls to Measure Voters' Preferences and Partisanship." British Journal of Political Science 43: 845-875.

National Commission on Civic Education (NCCE). 2015. "Assessing the Effectiveness of District Assemblies in Ghana's Democracy."

Olken, Benjamin. 2007. "Monitoring Corruption: Evidence from a Field Experiment in Indonesia." Journal of Political Economy 115(2): 200-249.

Oster, Emily. Forthcoming. "Unobservable Selection and Coefficient Stability: Theory and Evidence." Journal of Business Economics and Statistics.

Pressman, Jeffrey L., and Aaron Wildavsky. 1974. Implementation. Berkeley: University of California Press.

Rasul, Imran, and Daniel Rogger 2016. "Management of Bureaucrats and Public Service Delivery: Evidence from the Nigerian Civil Service." Forthcoming, Economic Journal.

Reinikka, Ritva, and Jakob Svensson. 2004. "Local Capture: Evidence from a Central Government Transfer Program in Uganda." Quarterly Journal of Economics 119(2): 679-705. 
Riker, William, and Steven Brams. 1973. "The Paradox of Vote Trading." American Political Science Review 67(4): 1235-1247.

Robinson, James A., and Ragnar Torvik. 2005. "White Elephants." Journal of Public Economics 89: 197-210.

Robinson, James A., and Thierry Verdier. 2013. "The Political Economy of Clientelism." Scandinavian Journal of Economics 115(2): 260-291.

Samuels, David. 2002. "Pork Barreling Is Not Credit Claiming or Advertising: Campaign Finance and the Sources of the Personal Vote in Brazil." Journal of Politics 64(3): 845-863.

Today Newspaper. 2015. "Election of MMDCEs: Ahwoi got it wrong-Nduom." 25 August. 〈http://www.ghanaweb.com/GhanaHomePage/NewsArchive/Electionof-MMDCEs-Ahwoi-got-it-wrong-Nduom-377412〉, accessed 25 August 2015.

TV3 Network. 2015. "Mahama calls for moderation in demands on gov't." 〈http://www.ghanaweb.com/GhanaHomePage/NewsArchive/artikel.php?ID= $353332\rangle$, accessed 4 July 2015.

Vanguard News. 2016. "19,000 projects abandoned in Nigeria, ex-BPP DG tells Senate." 〈http://www.vanguardngr.com/2016/05/19000-projects-abandonednigeria-ex-bpp-dg-tells-senate/ $\rangle$, accessed 11 August, 2016.

Weghorst, Keith R., and Staffan I. Lindberg. 2013. "What Drives the Swing Voter in Africa?" American Journal of Political Science 57(3): 717-734.

Weingast, Barry, and William Marshall. 1988. "The Industrial Organization of Congress; or, Why Legislatures, Like Firms, Are Not Organized as Markets." Journal of Political Economy 96(1): 132-163.

Whitfield, Lindsay. 2009. "'Change for a Better Ghana': Party Competition, Institutionalization and Alternation in Ghana's 2008 Elections." African Affairs 108: 621-641. 
World Bank. 2011. "Curbing Fraud, Corruption, and Collusion in the Roads Sector." Washington, DC: June. 
Appendix A Sample Annual Progress Report

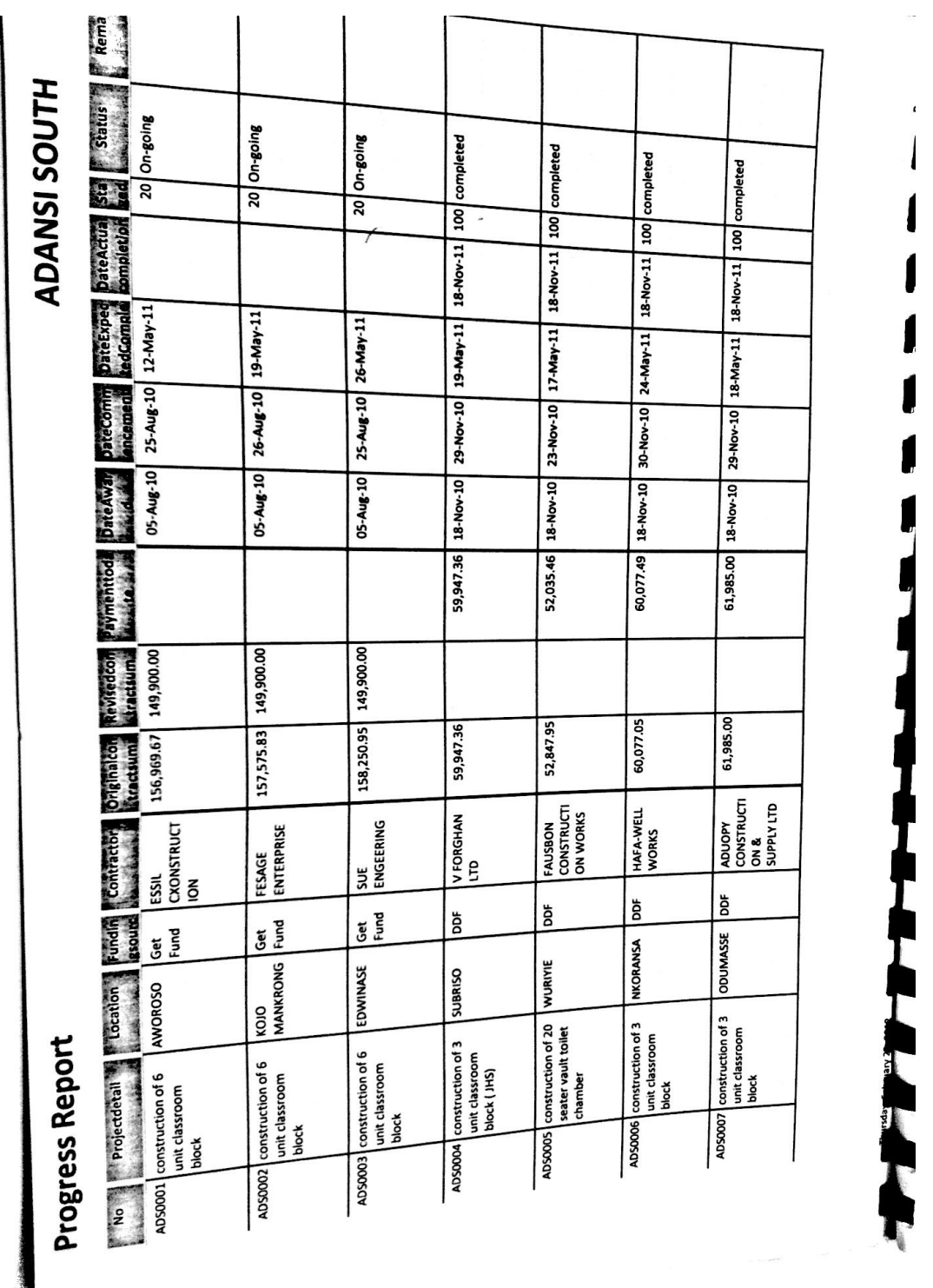




\section{Appendix B Sample balance}

The Annual Progress Reports (APRs) used to construct the database had to be located in hard or soft copy in the offices of the National Development Planning Commission (NDPC) in Accra or of the Regional Coordinating Councils (RCCs) in the ten regional capitals. Altogether 479 APRs were located. The maximum notional number of APRs for the period 2011-13 would be 602: 170 for 2011, 216 each for 2012 and 2013. Of these, 407 APRs contained project tables with sufficient information to be entered into the database. The final database thus covers 67.6 percent of possible district-year observations.

There is little evidence that missing reports are correlated with district characteristics. Figure A1 plots the unweighted means and 95 percent confidence intervals of a wide range of district characteristics, by the number of APRs that are missing for each district. The most important balancing test is for average annual project completion, this study's main dependent variable. Although it is not possible to calculate this for districts with all three APRs missing, there is no statistically significant difference in average project completion rates across districts with different levels of APR completeness.

The sample also appears to be balanced across the other variables reported in Figure A1. In addition to a wide range of demographic, social, and economic variables drawn from the 2010 Population and Housing Census, this includes: districts' scores on the Functional and Organizational Assessment Tool (FOAT) evaluation undertaken to assess districts' compliance with a set of procedural requirements as part of the allocation and disbursement procedure for DDF funds; the vote share in the district of the National Democratic Congress (NDC), which was the ruling party during the sample period, from the 2008 presidential elections; and budget size, as measured by the total revenue of the district in 2013. There are no apparent patterns across reporting completeness in any of the variables examined, so there is no evidence that the sample coverage of the APR database is biased. 
Figure A1: APR sample balance on selected variables
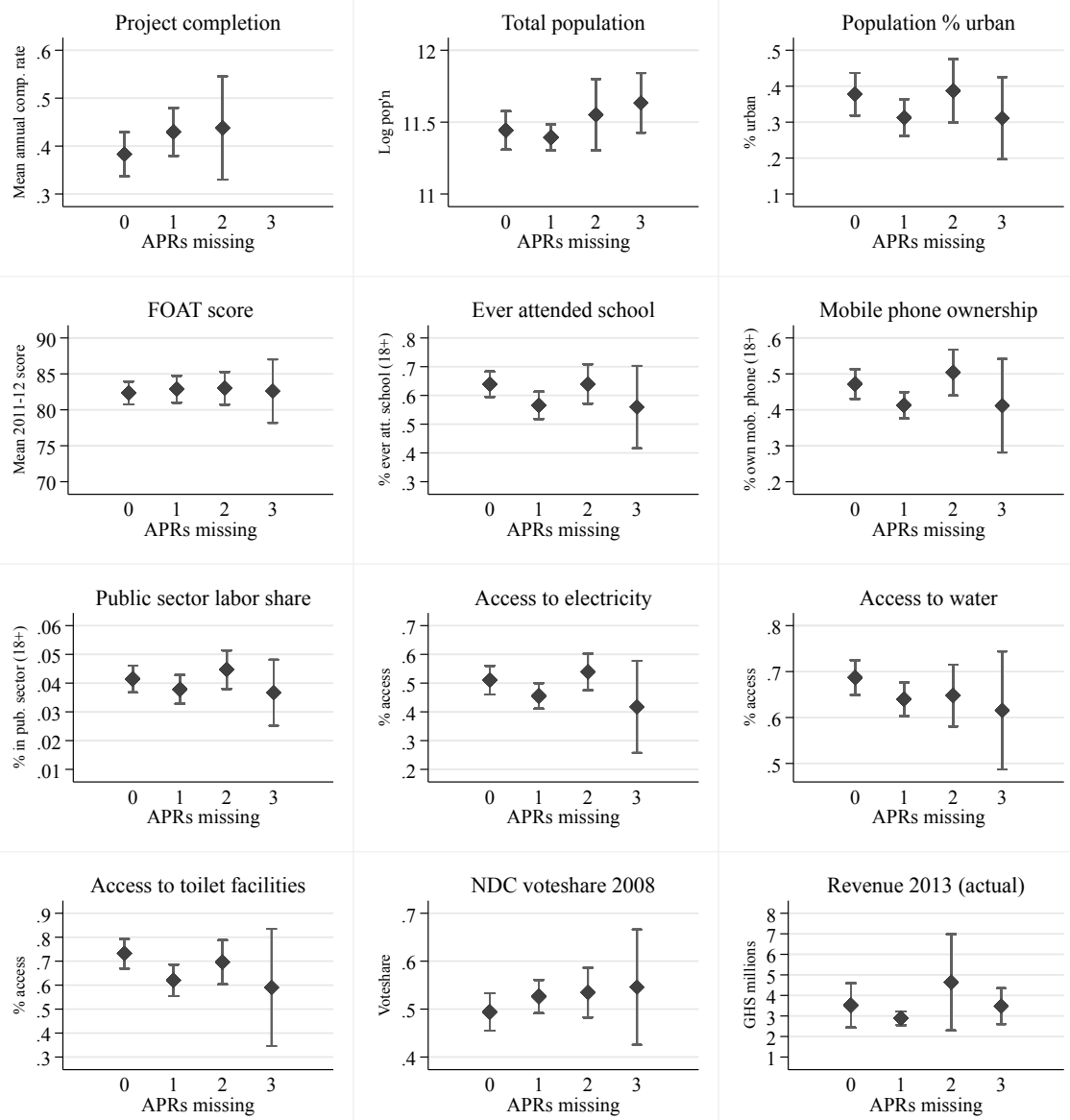

Note: Mean and $95 \%$ confidence intervals shown for each group of districts. Access to electricity is percentage of individuals reporting using mains electricity for lighting; access to water is percentage reporting using pipe-borne, borehole, or public tap water for drinking; access to toilet facilities is percentage using a WC, KVIP, pit latrine, or public toilet facility (all from Population and Housing Census 2010).

Table A1: Coverage of key variables in dataset

\begin{tabular}{llllll}
\hline \multirow{2}{*}{ Variable } & \multicolumn{2}{c}{ Non-missing } & & \multicolumn{2}{c}{ Non-missing } \\
& Obs. & Pct. & Variable & Obs. & Pct. \\
\hline Project title & 14,246 & $100.0 \%$ & Contract sum & 9,869 & $69.3 \%$ \\
Completion status & 13,339 & $93.6 \%$ & Commencement date & 5,518 & $38.7 \%$ \\
Fund source & 11,226 & $78.8 \%$ & Completion date (expected) & 5,061 & $35.5 \%$ \\
Location & 11,326 & $79.5 \%$ & Completion date (actual) & 1,424 & $10.0 \%$ \\
Contractor & 9,319 & $65.4 \%$ & Expenditure to date & 6,224 & $43.7 \%$ \\
\hline
\end{tabular}

Note: See Appendix C for full variable descriptions.

Percentages are as percent of total $(n=14,246)$. 
Due to the inconsistent reporting formats used by districts in producing their APRs, many observations are missing important variables, thus restricting the effective sample for certain types of analysis. Table A1 gives an indication of this for a selected number of variables. Although this affects the types of analysis that can be done on the data, there is no indication that the missing variables are anything other than a result of districts' use of different reporting formats. 


\section{Appendix C Variable coding}

All APR database variables were coded algorithmically from text strings by defining a set of word or phrases corresponding to values; the particularities of this process for each variable, along with other relevant data and coding notes, are detailed below. Project numbers and statistics in this appendix are given at the point of coding, and thus may differ from those in the final database from which repeat observations and non-infrastructure projects have been excluded.

Fund source Project fund source was constructed from APR entries for project's fund source for nearly all observations, although in a small number of cases (178, or 1.1 percent) there was no dedicated entry for fund source but fund sources were named in the project title. These were combined, and then coded into fund source categories according to a set of text strings commonly occurring in the data - e.g. for DACF, these were "DACF", "COMMON FUND", "D A C F", and "CF". All projects where the fund source was listed as the district itself were coded as using internally generated funds (IGF), together with those where IGF was directly identified as the fund source. A small number of projects (143) were funded by the local Member of Parliament (MP) using the small portion allocation of the DACF which is disbursed to them as a constituency development fund; these were coded under "Other" rather than DACF because they are selected and implemented separately. All projects with more than one identifiable fund source (about 3 percent) were coded as "Multiple".

Project type Project type was constructed using sets of commonly used text strings in the project title to first group projects into sixteen types of infrastructure projects:

- Agriculture: dams, irrigation, dug-outs;

- Borehole: boreholes, wells;

- Clinic: clinics, health centres, hospitals, wards;

- Construction - other: abattoirs, computer centers, libraries, taxi ranks, 
lorry parks, community centers, sports stadiums, light industrial areas, warehouses;

- Culvert: culverts, drains, ditches, gutters;

- Electricity: electrification, substations;

- Latrine: latrines, Kumasi ventilated improved pits (KVIPs), toilets, water closets;

- Market: market stalls, stores, sheds, meat shops;

- Office: administration blocks, assembly/town/council halls, courts, police stations, fire stations;

- Road: roads (paved, graveled, or dirt), bridges, spot improvements, speed humps, paving works;

- School: classroom blocks, kindergartens, nurseries, early childhood development centres;

- School - other: dormitories, dining halls, hostels, school feeding kitchens;

- Staff housing: bungalows, guest houses, accommodation blocks, residences, quarters;

- Streetlights

- Waste management: refuse dumps, rubbish storage; and

- Water: water systems, water harvesting, water supply, reservoirs and storage, pipe-borne water works, water distribution.

In addition, two categories of non-infrastructure projects were constructed but not included in the analysis:

- Procurement: purchase, supply, distribution, and furnishing (e.g. tractors, desks, computers), acquiring land for projects, equipment of facilities; and 
- Services: a wide variety of activities related to service-provision and other non-infrastructure activities, e.g. training, vaccination campaigns, capacity building, tax collection, celebrations, monitoring, public education, sponsoring.

The guiding principle in distinguishing between infrastructure and noninfrastructure projects was that projects involving physical transformation were coded as infrastructure (e.g. building a classroom block), whereas projects consisting only of related activities that did not themselves involve physical transformation (e.g. acquiring land to build a classroom block, supplying a classroom block with textbooks) were coded as non-infrastructure.

This algorithmic coding resulted in unique project types for 74.4 percent of projects, while 12.8 percent were not assigned a type and another 12.8 percent were assigned two or more types. These 5,569 projects were manually inspected and disambiguated if possible, or if the project genuinely straddled two types it was coded as "multiple".

Finally, the category "school" was sub-divided into six categories according to the size of the classroom block: five categories for 2-, 3-, 4-, 6-, and 12-unit classroom blocks, and a sixth residual category for classroom blocks of indeterminate size, or reported projects which actually involved more than one discrete structure (e.g. construction of two 3-unit classroom blocks). Number of units was coded algorithmically by defining a set of 41 common text string permutations used to denote construction of a single classroom block (e.g. "1NO 3-UNIT [CLASSROOM BLOCK]", "[CONSTRUCTION] OF 3-UNIT [CLASSROOM BLOCK]").

Prior to analysis, projects with missing type or coded as "services", "procurement" were dropped. The project categories used in the analysis therefore comprise the fifteen non-school infrastructure types listed above; six types of schools (five according to classroom block size, and one residual category); and the type "multiple" comprising all projects that could not be manually coded into a unique type. 
Construction type Project titles often include a phrase that identifies whether the project constitutes new (greenfield) construction, or repair, maintenance, renovation, or rehabilitation of an existing project that had been completed previously. The former category was coded as projects including the general text string "CONSTRUCTION OF" and abbreviations or misspellings of this; project type-specific construction verbs such as "DRILLING OF", "PAVING", and "SPOT IMPROVEMENT"; and strings indicating that the project is a greenfield project in its second or subsequent year, such as "COMPLETION OF", "CONTINUE", and "CLADDING". (The APRs are inconsistent in the extent to which they alter these prefaces for a given project across years (i.e. whether they change "CONSTRUCTION OF" in the first year of a project to "COMPLETION OF" in its second year), so these were coded together as greenfield projects.) Project titles containing general phrases such as "MAINTENANCE", "REPAIR", "RENOVATION", and "REHABILITATION", or project type-specific phrases such as "DESILTING", "RE-ROOFING", "RESURFACING", and "RESHAPING" were coded as maintenance/repair/renovation projects. Altogether 76.4 percent of projects were coded as greenfield construction, 11.9 percent as maintenance/repair/renovation, and the remaining 11.6 percent could not be uniquely identified as either type.

Project completion Project completion was coded as a binary variable by combining information from three raw variables, of which one or two are typically reported in each APR: ProjectStatus (e.g. "COMPLETED", "INSTALLED AND IN USE," "100 WORK DONE"), Remarks (similar), and PercentWork (on the scale 0-100; 100 coded as complete). Projects were coded as complete if they were at a stage where physical construction work had been completed, regardless of whether they had been formally handed over, furnished, commissioned, and put into use - for example "COMPLETED YET TO BE FURNISHED AND COMMISSIONED" was coded as complete. This yielded a unique completion coding for 91.6 percent of observations; the remainder were disambiguated by visual inspection if possible, and given a missing value if it was impossible to 
determine the project's status conclusively.

Although the gap between physical completion and putting the facility into use is of potential interest, physical completion was chosen as a cutoff point for the purposes of the APR database because: 1) the status of post-construction activities like furnishing, commissioning, and use are reported inconsistently in the APRs; and 2) the analytical focus of this paper is on infrastructure project construction, not subsequent service provision using those facilities.

Contractor A total of 6,798 unique contractor names are listed in the APR database for 10,701 infrastructure projects. However, many of these are clearly the same contractor but with different spellings (e.g. "WRKS" for "WORKS"), abbreviations (e.g. "LTD." for "LIMITED"), or omissions (e.g. dropping "LIMITED" or "INC."). In order to combine these, contractor names were stripped of these and other generic elements of company names (e.g. "ENTERPRISE", "TRADING", "MESSRS.", "M/S", "COMPANY"), as well as punctuation marks and spaces. This reduced the number of unique contractor names from 6,798 to 5,113 . Using these corrected contractor names rather than the raw names slightly changes the point estimates on fund source regression coefficients, but not the differences between these coefficients, which are the quantities of interest.

District In mid-2012, 45 of Ghana's 170 districts were split to create 46 new districts (one district was split into three), leaving a total of 216 districts. The 46 new districts were all entirely contained within a single parent district, so there was no realignment of borders between districts. The 2011 and 2013 APRs thus reflect the 170 and 216 districts, respectively. For 2012 districts reported according to the new (216) district names, although many of the newly created districts did not report as they had only been in existence for approximately six months and were still waiting offices, personnel, etc. This creates some concern about duplications or omissions in the reporting of projects in split districts that started prior to the split, and it is unclear how consistently these matters were handled across districts. However, restricting the sample to districts that 
did not split in 2012 does not affect any of the results presented above, and the regression results include district-year fixed effects that would capture any disruption caused by these administrative splits, so the potential data concerns created by the district splits do not appear to affect the analysis.

For purposes of project linking and fixed effects, the post-split "parent" district (the one that maintained the existing district capital, political leadership, and the majority of its administrative staff) is treated as the same district as the pre-split combined district, regardless of whether it changed its name, while the new "child" district is treated as a new district.

The other secondary data sources drawn on by this paper differ in whether they report the old 170 or new 216 districts for 2012. This means that in some cases (e.g. with budget data) APR data from a post-split 2012 district is matched to other secondary data from a pre-split 2012 combined district. The 2010 Population and Housing Census initially used the 170 districts but has been recoded to correctly reflect the new 216 districts for the analysis years 2012 and 2013.

Classroom block additional facilities For all classroom blocks for which it was possible to identify the number of units $(2,3,4,6$, or 12$)$, three indicator variables representing additional facilities included in the project were defined: latrines and toilets (project titles including the strings "LATRINE", "TOILET", "KVIP", etc.); offices/stores/libraries ("OFFICE", "STORE", "COMMON ROOM", "LIBRARY"); and general ancillary facilities (various spellings and abbreviations of "ANCILLARY"). These variables were not coded as mutually exclusive, although it is not common for one project to combine multiple types of ancillary facilities. A residual variable was defined for the 38.0 percent of projects that do not appear to include any of these ancillary facilities. 


\section{Appendix D Attrition}

Because very few districts assign unique tracking numbers to projects, linking projects across years had to be done manually. For each district for which all three years of data were available, records of projects coded as being in the same location (e.g. village, neighborhood) in different years were visually inspected according to their project title, fund source, completion status, contract sum, and other potentially identifying information, and linked if they were obviously the same project. Conditional on being incomplete in 2011 or 2012, only 33.8 percent of projects could be identified in the following year, indicating a high degree of attrition in reporting and linking. This gives rise to two concerns: first, differential attrition rates across fund sources could bias the within-district estimates of fund source completion rates. ${ }^{39}$ Second, attrition is likely to be correlated with project completion (if bureaucrats stop reporting unfinished projects that have been abandoned) and thus poses a challenge for estimating the overall completion rate.

To investigate the first possibility, I construct an attrition indicator variable equal to one if a project that is incomplete in 2011 or 2012 can be linked to the same project's record in the following year (2012 or 2013, respectively), and zero otherwise. This variable is defined only for projects in districts that have three years of APR data. I then use this as the dependent variable in an attrition probability model, estimated as a linear probability model, where the key variables of interest are fund source indicator variables.

The results are presented in Table A2. Column 1 estimates the model with no controls and indicator variables only for the three major fund sources; Column 2 adds the baseline set of district-year and project type fixed effects, plus project characteristics; and Column 3 estimates the model with community fixed effects.

\footnotetext{
${ }^{39}$ Attrition rates also vary across districts, and it is possible that districts interpret the reporting mandate in slightly different ways: some may report all projects that were underway in the district, whether or not they were active during the year, while others may only report projects that were active or included in annual budgets. However, this does not pose a major threat to this paper's main analysis, as the district fixed effects would cancel out district-level differences in attrition.
} 
Table A2: Attrition probability by fund source

\begin{tabular}{lccc}
\hline & $(1)$ & $(2)$ & $(3)$ \\
\hline Gov't-funded & -0.033 & -0.012 & -0.010 \\
& $(0.069)$ & $(0.046)$ & $(0.078)$ \\
Centralized & 0.019 & -0.047 & -0.002 \\
& $(0.066)$ & $(0.045)$ & $(0.115)$ \\
\hline District-Year fixed effects & & Yes & \\
Community fixed effects & & & \\
District-Year groups & & 71 & 496 \\
Community groups & 0.002 & 0.518 & 0.812 \\
$R^{2}$ & 915 & 915 & 807 \\
$N$ &
\end{tabular}

Note: Dependent variable is project attrition. All specifications include: fixed effects for 22 project types, with schools grouped by number of classrooms; construction type (construction or maintenance); and indicators for number of years since project start. Year fixed effects included in Column 3. Huber-White robust standard errors clustered by district-year in Columns 1-2 and by community in Column 3. Constant term not shown.

The differences among the coefficients on the three major fund sources are small and are not statistically significant in any of the specifications.

To address the second concern, I estimate three different sets of completion rates, which are almost identical for projects' first year but diverge thereafter:

- Upper bound. Projects are classified into years (1-3) according to their reported year of commencement (e.g. a 2012 observation of a project that started in 2011 is in its second year). No correction is made for attrition. Sample is all projects with non-missing commencement year.

- Middle estimate. Projects are classified into years according to manual linking (see above). Incomplete projects that cannot be traced to the subsequent year are treated as missing in the subsequent year (i.e. no correction is made for attrition). Projects that have not been linked to an observation from previous year are assumed to be in their first year. Sample is all projects from districts for which all three years of data are available. This is the method used in the main body of the paper.

- Lower bound. Same as middle estimate, but incomplete projects that cannot be traced to the subsequent year are assumed not to have been 
Figure A2: Alternative completion rate estimates

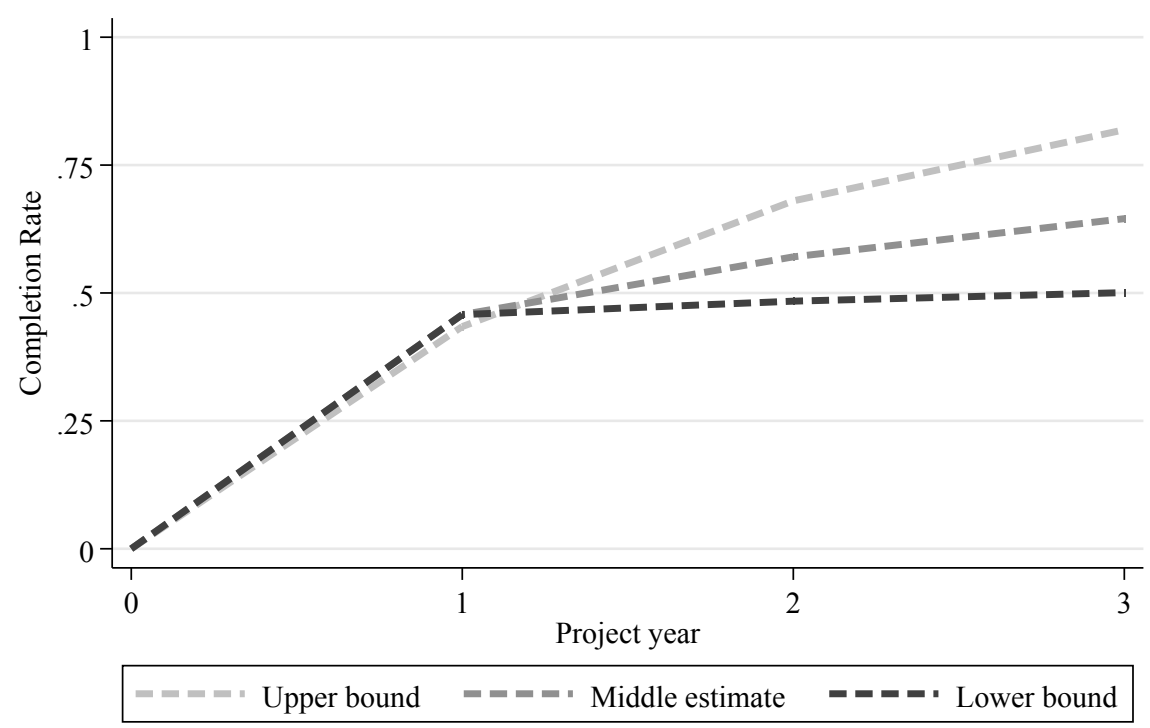

Note: See text for details of methodology.

finished (i.e. attriting observations are treated as incomplete).

The upper bound estimate will be biased upward if unfinished/abandoned projects are more likely to attrite from the dataset than completed projects, which is probable. Likewise, the lower bound estimate will be biased downward if untraceable projects are actually completed in the subsequent year but not reported, or if the projects were completed and reported but not linked by the manual tracing methodology. The middle estimate is situated between these two but may also be biased, although the direction of this bias is unclear a priori. To the extent that the middle and lower estimates incorrectly group projects that are in their second or subsequent years but are appearing in the dataset for the first time as first-year projects, the first-year completion rates may be biased; in practice however this bias appears to be small, as the first-year completion rates are very similar under all three estimates.

Figure A2 presents the three-year completion rates using these different estimation methods. The differences in the second and third years among the 
methods are large, although the completion hazard rate continues to decrease over time across each methodology.

Figure A3: Project completion by fund source - alternative estimates

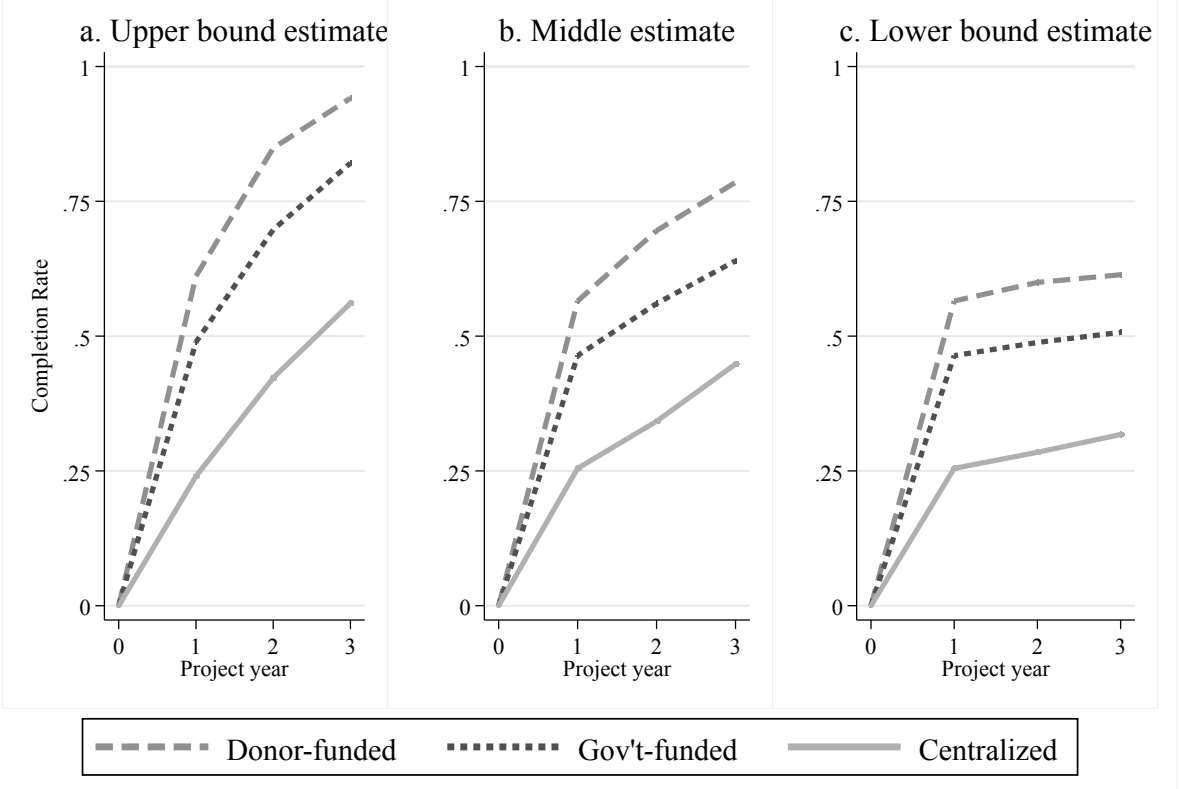

Note: See text for details of methodology.

However, Figure A3 shows that the differences across fund sources vary little across the estimation methodologies. This provides further reassurance that the main findings of the paper are not affected by attrition.

Finally, the attrition in linking projects from year-to-year suggests that the low rates of correspondence between district medium-term plans and projects actually implemented (5.7 percent of projects in district plans could be located in the APR database, and 3.8 percent of projects reported in the APR database could be identified in the plan) could overstate the true variance. Since the same linking methodology was used for the plan-APR linking as for the year-to-year linking within the APR database, a conservative approximation of the potential extent of bias can be generated using the observed attrition rate within the APR database (66.2 percent). Under the extremely conservative assumption that all of this attrition is due to error in the linking process (rather than districts 
ceasing to report on projects on which no new progress had been made), then the plan-APR linking rates could represent only 33.8 percent of the true rate of correspondence. This would roughly triple the true rate of correspondence, to 16.9 percent of planned projects that were implemented and 11.2 percent of implemented projects that were planned. Even these generous estimates are still extremely low in absolute terms, however, and would still support the conclusion that there is a high degree of temporal instability in district collective expenditure priorities. 


\section{Appendix E Validating completion measures}

This appendix reports the numerous steps taken to address concerns about bias in districts' reported levels of project completion. The project completion rates estimated from the APR database used in this paper are in a similar range to figures compiled on smaller project samples through (1) a donor-commission independent evaluation report, (2) an internal Ministry of Education database compiled through separate means, and (3) a Ghana Audit Service monitoring report. I also (4) conducted two sets of site visits to small sub-samples of projects, 128 in total, and found no evidence of systematic bias in reporting. On the specific concern that the finding of systematic under- or delayed payment to contractors may be biased by over-reporting of physical completion or under-reporting of financial expenditure, I (5) present a Ghana Audit Service audit report of 100 projects that found under-payment to be pervasive and over-payment almost non-existent, and (6) show evidence that underpayment to contractors does not appear to be explained by normal delays in payment processing or difficulties in tracking financial expenditure across years. Finally, I (7) argue that districts' have little incentive to misreport completion in the APRs since these reports are not used for accountability purposes, and even if there were some degree of bias in completion reporting, an opinion that is shared by central government auditors. Furthermore, in order to bias the key predictions of the collective choice and clientelism theories, any bias in completion reporting would have to be within rather than across districts, differential across fund sources, and the extent of this difference would have to be correlated with district partisan vote shares.

(1) An independent, donor-commission evaluation report on a sample of 90 projects across 28 districts in late 2013 (Salasan Consulting 2013) found that 78 percent of DDF projects were completed (compared to a three-year completion rate of 78.5 percent from the APR database) and 53 percent of DACF projects were completed (compared to a three-year completion rate of 64.0 percent from 
the APR database). These completion rates are not directly comparable, since no information is given on the start date or expected completion time of these projects and the sample is non-representative, but it is reassuring that the completion rates are nonetheless in a similar range.

(2) The Ministry of Education maintains its own internal monitoring database of 1,146 GETFund projects, which is compiled by central officials rather than the district officals who write APRs. It reports that of 6-unit classrooms and dormitories started between 2009 and 2013 nationwide, only 36.6 percent had been completed. It is not possible to disaggregate this by year of project commencement, and the date of reporting is not indicated (these figures are based on a database provided by the Ministry of Education in January 2015). (3) In addition, the Ghana Audit Service reports that a June 2013 monitoring effort of 179 school projects in seven regions started in 2010 and 2011 found that 27 percent were complete, despite scheduled completion times of six to twelve months - a similar length to most GETFund projects in the APR database (Ghana Audit Service 2014, 290). While these estimates differ slightly in timespan and project coverage, they are in the same range as APR database estimates that GETFund projects have one-year completion rates of 25.4 percent and threeyear completion rates of 44.8 percent.

(4) Though the high cost of locating and travelling to projects in remote areas made it impractical to conduct visits to a representative sample of projects in each district (hence the need to rely on administrative data), I conducted physical site visits to a small sub-sample of projects that had been coded as complete in 2013, spread across four randomly selected districts in two regions. Seventeen of the twenty projects were fully complete, while the remainder were functionally complete but with minor areas of incompleteness (e.g. no windows, untiled floors, holes in roof, some roofing remaining to be done). Sixteen of the projects were in full use; of the remaining four, one was in partial use, one was out of use because of cracks and accessibility issues, and one had not been commissioned yet. The site visits were conducted in October 2014, ten 
months after the project had been reported as complete; in only one case did people present at the project site report that the project had actually been fully completed in 2014 rather than 2013. The physical evidence from this limited sample suggests that while construction quality, maintenance, and finishing may be issues, there is little evidence that districts' reports of substantial aspects of physical construction are systematically biased towards completion.

In January-March 2017 I conducted a second set of site visits to 108 projects that were reported on in 2015 (selected using preliminary data drawn from the 2015 APRs). The projects were randomly selected from 12 districts in three regions, covered the three most common project types (schools, latrines, and staff housing), and included projects that had been reported as incomplete as well as complete. A research assistant was trained by Ghana government engineers to estimate percentage completion status. In total, 63.6 percent of actual project percentage physical completion estimates were within 10 percentage points of the estimate reported in the APR, 27.3 percent had significantly higher physical completion than reported, and 9.1 percent had significantly lower physical completion rates than reported. Of the eight projects for which physical progress had been overreported, in only three was the gap between estimates larger than 25 percentage points. The overreported projects were spread across fund sources: two from the GETFund ("centralized"), two from the DACF ("governmentfunded"), two from the DDF ("donor-funded"), one from district own revenue, and one had no fund source data.

To estimate how much influence the handful of projects for which completion was over-reported might have on the missing expenditure calculations used in discussing the incidence of over- versus under-payment, for these 108 projects I calculate the missing expenditures variable in two ways: first, by using the physical completion status as reported in the APR, as in the main text; and second, using a "corrected" physical completion status measure in which I replace the self-reported completion percentage with the "correct" estimate from the site visit. This is the most conservative possible way to implement this correction, 
since it assumes that all measurement or reporting error on physical completion is positive (i.e. overestimates completion). Compared to the corrected measure, the APR dataset overstates the percentage of projects where missing expenditures are significantly negative (underpayment) by 8.3 percent (and has no impact on the percentage of projects with positive missing expenditures). The key ratio presented in the main text was that underpayment by 10 percent or more is 3.2 times more frequent than overpayment by 10 percent or more for incomplete projects. If the percentage of projects with significant underpayment were actually 8.3 percent lower due to over-reporting of completion, then this ratio would be 3.0 instead of 3.2. Even under the most conservative assumptions about potential over-reporting of physical completion data, then, the key qualitative finding of the analysis still holds: underpayment for work done is far more common than overpayment for work done.

(5) In 2015 the Ghana Audit Service undertook intensive performance audits of a (non-representative) sample of 100 projects from 50 districts around the country. On the subject of "payment for works", it concluded the delayed payment and underpayment to contractors was pervasive: "Payment to contractors was a serious problem in all the assemblies. In most cases it was [only] the advance mobilization payment that was made on time. All other payments were not regular as envisaged by the conditions of contract." (Ghana Audit Service 2016a, 26) In contrast, the only instance of overpayment it noted - in a section on "Uncommon But Significant Audit Findings" - was the payment of an entire bill of quantities line item for a library that was constructed smaller than had been specified, resulting in overpayment of GHS 18,610.82 ${ }^{40}$ (Ghana Audit Service 2016a, 28). A senior auditor who worked on the project confirmed that such instances of overpayment were rare: "I don't think it was a common thing. I don't think I saw that in the areas I went... That may have been if they were falsifying information on the payment certificates. There was one district that had something like that. It wasn't something that was cutting across all.

\footnotetext{
${ }^{40}$ Equivalent to USD 4,561.48 using the exchange rate of June 1, 2015.
} 
Maybe two or three" (Telephone interview, 27 January, 2017).

(6) Districts usually have a period of 28 days after contractors have submitted payment requests in which to inspect work and make payment; the length of this period can vary by contract. Since both financial and physical status are reported by districts at the end of the year, this time lag could exaggerate the true extent of underpayment if payment delays were normal or merely a short-term phenomenon. If this measurement issue were driving the over/under-payment ("missing expenditures") measure, then projects completed earlier in the year should have lower rates of underpayment than projects completed later in the year. However, there is no correlation $(-0.0026, p=0.966)$ between projects' reported month of completion and missing expenditures. Thus, negative values really do seem to be measuring severely delayed payment or non-payment rather than normal lags in processing payment.

(7) Finally, district officials would have no incentive to lie in compiling their APRs, since the APRs are not submitted directly to any of the funding institutions, and prior to the compilation of this database were not being used by these institutions for monitoring purposes. The reports were subject only to a perfunctory check by central government officials and there are no reported instances of any district-level being punished based on information reported in an APR. Scrutiny of district operations is somewhat more intense in terms of financial management due to the Ghana Audit Service's annual audits, but if anything this provides an incentive for district-level officers not to misreport the financial status of projects on APRs. This is because the information on financial expenditure in APRs is easy to verify against other payment records, so any discrepancy would be likely to be noticed and attract unwanted attention. In an interview, a senior Audit Service official expressed skepticism regarding district officials' incentives to misrepresent projects' physical or financial status in the APRs: "I don't think any of them will represent false information. It's not something that really happens actually... They don't have an incentive to lie at all." (Telephone interview, 27 January, 2017) 
Furthermore, it is important to note that data quality and reporting honesty are most likely to vary at the district level, since this is the level at which APRs are written. Since this paper's analysis focuses mainly on within-district variation, however, misreporting would only bias the key results if it were differential across fund sources and the extent of this across-fund source difference was correlated with partisan vote shares.

\section{Supplementary References}

Salasan Consulting. 2013. "The District Development Facility (DDF) and the District-Wide Assistance Transition Project (DWAP) in Ghana: An Independent Review." August-September. 


\section{Appendix F Robustness}

\section{F.1 Robustness}

Table A3 presents the results of several robustness checks on the main results. To account for the binary dependent variable, Column 1 presents the baseline model from Equation 1 estimated with a random effects logit. The large number of district-year groups makes estimation with fixed effects unfeasible, hence the preference for the linear probability model throughout, but Column 1 shows that this estimator choice is not driving the results.

To address the concern that the project type fixed effects do not adequately control for heterogeneity in the physical characteristics of projects, Column 2 restricts the sample to schools (with project type defined by the number of classrooms in the school) and introduces controls for the presence of ancillary facilities attached to the school buildings. The estimated $\hat{\tau}^{G o v^{\prime} t}$ remains large and statistically significant, and significantly greater than $\hat{\tau}^{\text {Central }}$.

Another potential concern is that the use of annual project completion rate as dependent variable might be biasing the estimated fund source effects, as could be the case if project completion rates declined over years since project start, if this led latter-year projects from some fund sources to remain in the sample, and if the project-year controls included in the regression did not adequately control for this effect. Column 3 therefore restricts the same to the subset of projects for which commencement dates are available, and thus for which it is possible to determine with certainty that they are in their first year of implementation. The point estimate of $\hat{\tau}^{G o v^{\prime} t}$ is almost unchanged from the baseline model in Table 2 Column 4, but loses statistical significance at conventional levels because the sample restriction dramatically increases the standard error of the estimate.

Another concern is that $\hat{\tau}^{G o v^{\prime} t}$ could be driven by some aspects of project size that are not captured by the project type controls and are correlated with project fund source and partisan alignment. To examine this, Columns 4 and 5 include controls for project contract sum and scheduled project duration, re- 
Table A3: Robustness checks

\begin{tabular}{|c|c|c|c|c|c|}
\hline & $\begin{array}{c}(1) \\
\text { Logit }\end{array}$ & $\begin{array}{c}(2) \\
\text { Schools }\end{array}$ & $\begin{array}{c}(3) \\
\text { First-year }\end{array}$ & $\begin{array}{l}(4) \\
\text { Cost }\end{array}$ & $\begin{array}{c}(5) \\
\text { Duration }\end{array}$ \\
\hline Gov't-funded & $\begin{array}{l}-1.179 \\
(0.271)\end{array}$ & $\begin{array}{c}-0.423 \\
(0.076)\end{array}$ & $\begin{array}{l}-0.210 \\
(0.133)\end{array}$ & $\begin{array}{l}-0.222 \\
(0.064)\end{array}$ & $\begin{array}{l}-0.392 \\
(0.077)\end{array}$ \\
\hline Centralized & $\begin{array}{l}-1.159 \\
(0.393)\end{array}$ & $\begin{array}{l}-0.377 \\
(0.082)\end{array}$ & $\begin{array}{l}-0.333 \\
(0.213)\end{array}$ & $\begin{array}{l}-0.160 \\
(0.084)\end{array}$ & $\begin{array}{l}-0.357 \\
(0.096)\end{array}$ \\
\hline Gov't-funded $*$ NDC vote share & $\begin{array}{l}1.266 \\
(0.508)\end{array}$ & $\begin{array}{c}0.573 \\
(0.160)\end{array}$ & $\begin{array}{c}0.252 \\
(0.289)\end{array}$ & $\begin{array}{c}0.176 \\
(0.126)\end{array}$ & $\begin{array}{c}0.553 \\
(0.197)\end{array}$ \\
\hline Centralized $*$ NDC vote share & $\begin{array}{l}-0.554 \\
(0.688)\end{array}$ & $\begin{array}{c}0.291 \\
(0.154)\end{array}$ & $\begin{array}{c}0.053 \\
(0.512)\end{array}$ & $\begin{array}{c}0.018 \\
(0.160)\end{array}$ & $\begin{array}{c}0.236 \\
(0.242)\end{array}$ \\
\hline Ancillary facilities & & $\begin{array}{l}-0.108 \\
(0.031)\end{array}$ & & & \\
\hline Toilet & & $\begin{array}{l}-0.026 \\
(0.044)\end{array}$ & & & \\
\hline Office/ store/ library & & $\begin{array}{c}0.026 \\
(0.028)\end{array}$ & & & \\
\hline $\operatorname{Ln}($ contract sum $)$ & & & & $\begin{array}{l}-0.134 \\
(0.016)\end{array}$ & \\
\hline Scheduled duration & & & & & $\begin{array}{l}-0.025 \\
(0.030)\end{array}$ \\
\hline District-Year RE & Yes & & & & \\
\hline District-Year FE & & Yes & Yes & Yes & Yes \\
\hline District-Year groups & & 305 & 147 & 276 & 140 \\
\hline$R^{2}$ & & 0.421 & 0.518 & 0.390 & 0.405 \\
\hline$N$ & 6460 & 2815 & 1110 & 4358 & 1955 \\
\hline
\end{tabular}

Dependent variable is project completion. All specifications include: fixed effects for 22 project types, with schools grouped by number of classrooms; construction type (construction or maintenance); and indicators for number of years since project start. NDC vote share 2008 is the ruling party's voteshare in the 2008 presidential elections in the district (or its antecedent district, for districts that split in 2012). Huber-White robust standard errors clustered by district-year. Constant term not shown.

spectively, although properly speaking both these measures of project size are post-treatment variables and so their inclusion could bias $\hat{\tau}^{G o v^{\prime} t}$ up or down. Again, these can only be estimated on restricted samples due to many districts not reporting these variables. The point estimates vary somewhat across specifications and samples, but the key interaction term results are unchanged.

As Hainmueller et al (2017) note, interaction models such as the one used in this article are often subject to problems of non-linearity and lack of common support. To address this issue, I implement Hainmueller et al's recommended "binning" procedure that allows for non-linear marginal effects and displays the common support of government- and donor-funded projects. As Figure A4 
Figure A4: Robustness of marginal effects

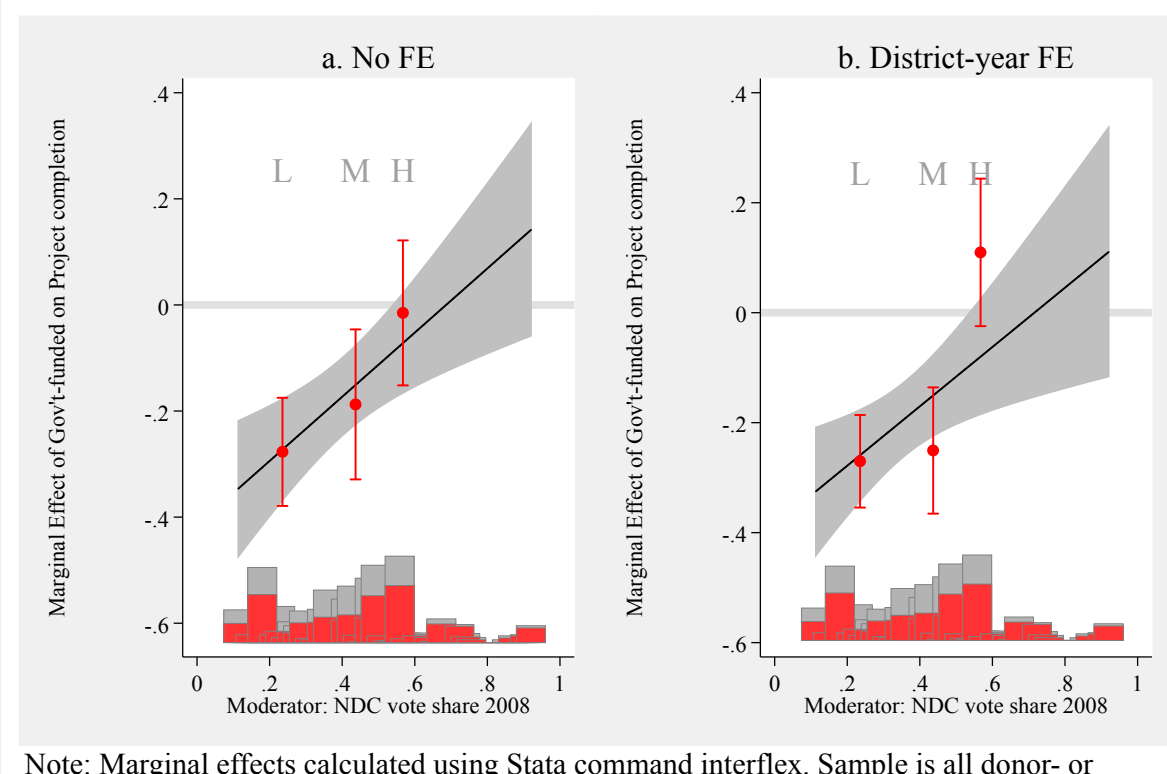

Note: Marginal effects calculated using Stata command interflex. Sample is all donor- or government- funded projects. Both graphs include controls described in Table A3. Robust standard errors clustered by district-year.

shows, there is a common support of projects from both fund sources across the spectrum of values for NDC vote share. Panel (a) of Figure A4 without district-year fixed effects shows no evidence of non-linearity, and a Wald test fails to reject the null of a linear marginal effect. When district-year fixed effects are added in Panel (b) there is some evidence that the marginal effect of government funding is concentrated in the lower and middle terciles of the distribution of NDC vote share, and the Wald test is rejected. This suggests that there could potentially be non-linearities or threshold effects in coalition formation and project priority stabilization. However, this article's key theoretical prediction is simply that the government-funded completion rate should be increasing in $N D C$ vote share relative to that of donor projects, and does not specify the functional form of this relationship, so this possibility is not inconsistent with the theory. Further exploring this would be an interesting topic for further research and possibly formal modelling. While Panel (b) suggests that the interaction between partisan alignment and project fund source may 
be stronger in some parts of the distribution than others, there is no evidence that the effect is non-increasing or significantly non-negative.

\section{F.2 Ethnicity}

The main body of this article uses district ruling party vote share to proxy for the ease of achieving efficient collective choice outcomes at district-level, for reasons described in Section, and shows that this proxy affects government-funded projects where expenditure decisions are taken at local level but not centralized projects. As a robustness check on the idea that non-completion is caused by district-level collective decisionmaking problems, Table A4 re-estimates Equation 1 using two measures of district ethnic diversity as alternative proxies for the difficulty of sustaining intertemporal bargains among district-level political actors. Since poor public good provision has often been attributed to ethnic diversity (Miguel and Gugerty 2005), ethnic diversity could serve as an alternative proxy for the efficiency of district-level collective choices over project distribution, although there is considerable disagreement in the literature over whether and when ethnic diversity reduces public good provision and the proposed mechanism is usually through collective action rather than collective choice (Glennerster, Miguel, and Rothenberg 2013). The two measures of ethnic diversity are: ethnic fractionalization, calculated as standard (e.g. Miguel and Gugerty 2005); and ethnic polarization, calculated following Montalvo and Reynal-Querol (2005). Both are calculated using the primary ethnic categories from Ghana's 2010 Population and Housing Census.

The estimated coefficients on the ethnicity-fund source interaction terms in Columns 1 and 2 imply that government-funded project completion is weakly decreasing in ethnic diversity relative to donor-funded project completion, while the effect on centralized projects is even weaker and actually positive-signed. These patterns are somewhat stronger for ethnic polarization than ethnic fractionalization, consistent with the idea that it is the political salience of ethnic diversity rather than diversity itself that is problematic for collective choice, 
Table A4: Ethnic diversity and fund source interactions

\begin{tabular}{|c|c|c|c|c|}
\hline & (1) & (2) & (3) & (4) \\
\hline Gov't-funded & $\begin{array}{l}-0.072 \\
(0.055)\end{array}$ & $\begin{array}{l}-0.024 \\
(0.074)\end{array}$ & $\begin{array}{l}-0.183 \\
(0.080)\end{array}$ & $\begin{array}{l}-0.139 \\
(0.098)\end{array}$ \\
\hline Centralized & $\begin{array}{c}-0.276 \\
(0.067)\end{array}$ & $\begin{array}{c}-0.288 \\
(0.082)\end{array}$ & $\begin{array}{c}-0.240 \\
(0.102)\end{array}$ & $\begin{array}{c}-0.251 \\
(0.120)\end{array}$ \\
\hline Gov't-funded * Ethnic fractionalization & $\begin{array}{c}-0.071 \\
(0.110)\end{array}$ & & $\begin{array}{c}-0.072 \\
(0.108)\end{array}$ & \\
\hline Centralized $*$ Ethnic fractionalization & $\begin{array}{c}0.054 \\
(0.126)\end{array}$ & & $\begin{array}{c}0.047 \\
(0.127)\end{array}$ & \\
\hline Gov't-funded $*$ Ethnic polarization & & $\begin{array}{c}-0.133 \\
(0.120)\end{array}$ & & $\begin{array}{l}-0.123 \\
(0.120)\end{array}$ \\
\hline Centralized $*$ Ethnic polarization & & $\begin{array}{c}0.062 \\
(0.124)\end{array}$ & & $\begin{array}{c}0.053 \\
(0.127)\end{array}$ \\
\hline Gov't-funded $*$ NDC vote share & & & $\begin{array}{c}0.240 \\
(0.116)\end{array}$ & $\begin{array}{c}0.233 \\
(0.117)\end{array}$ \\
\hline Centralized $*$ NDC vote share & & & $\begin{array}{c}-0.062 \\
(0.129)\end{array}$ & $\begin{array}{l}-0.058 \\
(0.132)\end{array}$ \\
\hline District-Year FE & Yes & Yes & Yes & Yes \\
\hline District-Year groups & 338 & 338 & 338 & 338 \\
\hline$R^{2}$ & 0.351 & 0.352 & 0.353 & 0.353 \\
\hline$N$ & 6460 & 6460 & 6460 & 6460 \\
\hline
\end{tabular}

Dependent variable is project completion. All specifications include: fixed effects for 22 project types, with schools grouped by number of classrooms; construction type (construction or maintenance); and indicators for number of years since project start. Ethnic fractionalization and polarization are calculated as standard in the literature (see Miguel and Gugerty 2005, Montalvo and Reynal-Querol 2005), using the primary ethnic categories from Ghana's 2010 Population and Housing Census; and NDC vote share 2008 is the ruling party's voteshare in the 2008 presidential elections in the district (or its antecedent district, for districts that split in 2012). Huber-White robust standard errors clustered by districtyear. Constant term not shown.

but even for polarization the differences across fund sources are not statistically significant: $p=0.269$ for the donor-government comparison, and $p=0.072$ for the difference between government-funded and centralized projects.

Columns 3 and 4 show that the point estimates and statistical significance of the interaction terms between project fund source and $N D C$ vote share are unaffected by the inclusion of the ethnic diversity interaction terms. The relevant collective choice problems - and means of resolving them - thus appear to be more closely associated with partisan politics rather than ethnic divisions, at least in the Ghanaian context. 


\section{Supplementary References}

Glennerster, Rachel, Edward Miguel, and Alexander D. Rothenberg. 2013.

"Collective Action in Diverse Sierra Leone Communities." The Economic Journal 123: 285-316.

Hainmueller, Jens, Jonathan Mummolo, and Yiqing Xu. 2017. "How Much Should We Trust Estimates from Multiplicative Interaction Models? Simple Tools to Improve Empirical Practice." Mimeo, 13 February.

Miguel, Edward, and Mary Kay Gugerty. 2005. "Ethnic diversity, social sanctions, and public goods in Kenya." Journal of Public Economics 89: 23252368 .

Montalvo, José G. and Marta Reynal-Querol. 2005. "Ethnic Polarization, Potential Conflict, and Civil Wars." American Economic Review 95(3): 796816. 